\title{
The interaction of $\mathrm{N}_{2} \mathrm{O}_{5}$ with mineral dust: aerosol flow tube and Knudsen reactor studies
}

\author{
C. Wagner ${ }^{1}$, F. Hanisch ${ }^{1, *}$, N. Holmes ${ }^{1, * *}$, H. de Coninck ${ }^{1, * * *}$, G. Schuster ${ }^{1}$, and J. N. Crowley ${ }^{1}$ \\ ${ }^{1}$ Max-Planck-Institut für Chemie, Mainz, Germany \\ *now at: Bayerisches Staatsministerium für Umwelt, Gesundheit und Verbraucherschutz, Rosenkavalierplatz 2, 81925 \\ München, Germany \\ ** now at: International Laboratory for Air Quality and Health, QUT Gardens Point, 2 George Street, Brisbane, 4001 QLD, \\ Australia \\ ${ }^{* * * *}$ now at: Unit Policy Studies of the Energy research Centre of the Netherlands, (ECN), VU University of Amsterdam \\ (IVM), Radarweg 60, 1040 AW Amsterdam, The Netherlands
}

Received: 7 September 2007 - Published in Atmos. Chem. Phys. Discuss.: 12 September 2007

Revised: 5 December 2007 - Accepted: - Published: 14 January 2008

\begin{abstract}
The interaction of mineral dust with $\mathrm{N}_{2} \mathrm{O}_{5}$ was investigated using both airborne mineral aerosol (using an aerosol flow reactor with variable relative humidity) and bulk samples (using a Knudsen reactor at zero humidity). Both authentic (Saharan, SDCV) and synthetic dust samples (Arizona test dust, ATD and calcite, $\mathrm{CaCO}_{3}$ ) were used to derive reactive uptake coefficients $(\gamma)$. The aerosol experiments (Saharan dust only) indicated efficient uptake, with e.g. a value of $\gamma(\mathrm{SDCV})=(1.3 \pm 0.2) \times 10^{-2}$ obtained at zero relative humidity. The values of $\gamma$ obtained for bulk substrates in the Knudsen reactor studies are upper limits due to assumptions of available surface area, but were in reasonable agreement with the AFT measurements, with: $\gamma(\mathrm{SDCV})=(3.7 \pm 1.2) \times 10^{-2}, \gamma(\mathrm{ATD})=(2.2 \pm 0.8) \times 10^{-2}$ and $\gamma\left(\mathrm{CaCO}_{3}\right)=(5 \pm 2) \times 10^{-2}$. The errors quoted are statistical only. The results are compared to literature values and assessed in terms of their impact on atmospheric $\mathrm{N}_{2} \mathrm{O}_{5}$.
\end{abstract}

\section{Introduction}

Estimates of emissions of mineral dust into the atmosphere presently lie at somewhat less than $2000 \mathrm{Tg}$ per annum (Lunt and Valdes, 2002; Tegen et al., 2002; Luo et al., 2003) making it an important component of the coarse fraction of atmospheric aerosol and explaining its significant impact on several aspects of atmospheric science including radiative forcing, and modification of photochemical cycles. The direct radiative forcing effect (due to scattering and absorption of incoming solar radiation) is accompanied by an indirect effect as clay and silica particles are effective condensation and ice nuclei (Sassen et al., 2003; Ansmann et al., 2005), which can ultimately affect cloud structure and precipitation patterns (Twomey et al., 1984). The latter effect will likely be modified by the physical state of the mineral dust particles, which will be influenced by chemical ageing during atmospheric transport. Evidence from field, laboratory and modelling efforts is increasing pointing towards an important role of mineral dust as provider of reactive surfaces for several trace gases. Interaction of mineral dust with atmospheric $\mathrm{NO}_{\mathrm{x}}-\mathrm{NO}_{\mathrm{y}}$ trace gases is particularly interesting due to its potential impact on photochemical ozone production. An increase in the nitrate content of dust during transport over polluted regions has been documented on several occasions (Nishikawa and Kanamori, 1991; Silva et al., 2000; Mori et al., 2003; Hwang and Ro, 2005; Matsuki et al., 2005) and model studies have confirmed that this is consistent with the uptake of reactive $\mathrm{NO}_{\mathrm{y}}$ traces gases such as $\mathrm{HNO}_{3}$ and $\mathrm{N}_{2} \mathrm{O}_{5}$ (Carmichael et al., 1996; Dentener et al., 1996).

The overall impact which heterogeneous reactions of $\mathrm{NO}_{\mathrm{y}}$ on mineral aerosol exert on tropospheric photochemical cycles, has been assessed in several combined aerosol/gasphase models (Zhang et al., 1994; Dentener et al., 1996; Phadnis and Carmichael, 2000; Song and Carmichael, 2001; Bian and Zender, 2003; Bauer et al., 2004). All models suggest a significant impact of $\mathrm{NO}_{\mathrm{y}}$ uptake on e.g. the partitioning of nitrate between the gas and particulate phase, the $\mathrm{NO}_{\mathrm{y}} / \mathrm{NO}_{\mathrm{x}}$ ratio and ozone concentrations.

Correspondence to: J. N. Crowley

(crowley@mpch-mainz.mpg.de)

Published by Copernicus Publications on behalf of the European Geosciences Union. 
$\mathrm{N}_{2} \mathrm{O}_{5}$ is generated in the termolecular reaction of $\mathrm{NO}_{2}$ with $\mathrm{NO}_{3}$, which is formed mainly by the reaction of $\mathrm{NO}_{2}$ with $\mathrm{O}_{3}(\mathrm{R} 1)$

$\mathrm{NO}_{2}+\mathrm{O}_{3} \rightarrow \mathrm{NO}_{3}+\mathrm{O}_{2}$

$\mathrm{NO}_{2}+\mathrm{NO}_{3}+\mathrm{M} \rightarrow \mathrm{N}_{2} \mathrm{O}_{5}+\mathrm{M}$

Although the fast photolysis of $\mathrm{NO}_{3}$ (lifetime is $\approx 1 \mathrm{~s}$ ) (Wayne et al., 1991) renders $\mathrm{N}_{2} \mathrm{O}_{5}$ formation inefficient during the day, $\mathrm{N}_{2} \mathrm{O}_{5}$ can be an important reservoir of $\mathrm{NO}_{3}$ and $\mathrm{NO}_{2}$ during night-time. At night, the relative concentrations of $\mathrm{N}_{2} \mathrm{O}_{5}, \mathrm{NO}_{3}$ and $\mathrm{NO}_{2}$ are controlled by the equilibrium described by the formation of $\mathrm{N}_{2} \mathrm{O}_{5}(\mathrm{R} 1, \mathrm{R} 2)$ and its loss due to thermal decomposition (R-2):

$\mathrm{N}_{2} \mathrm{O}_{5}+\mathrm{M} \rightarrow \mathrm{NO}_{2}+\mathrm{NO}_{3}+\mathrm{M}$

This equilibrium can be perturbed by changes in concentration of any one of the three trace gases, with loss of $\mathrm{N}_{2} \mathrm{O}_{5}$ expected to be important due to the well established reactivity of this acid anhydride towards aqueous or moist surfaces, resulting in nitrate formation (R3). The long photochemical lifetime and high solubility of nitrate/nitric acid result in large deposition rates and permanent removal from the atmosphere.

$\mathrm{N}_{2} \mathrm{O}_{5}+$ surface $+\mathrm{H}_{2} \mathrm{O} \rightarrow 2 \mathrm{HNO}_{3}$ (or nitrate)

The loss of $\mathrm{N}_{2} \mathrm{O}_{5}$ on an aerosol is thus recognised as an important removal process for $\mathrm{NO}_{\mathrm{x}}$ in many regions of the atmosphere (Chartrand and McConnell, 1999; Hendricks et al., 1999; Evans and Jacob, 2005). The direct reduction in $\mathrm{NO}_{3}$ and the indirect reduction of $\mathrm{O}_{3}$ (due to repartitioning of $\mathrm{NO}_{\mathrm{x}}$ to $\mathrm{NO}_{\mathrm{y}}$ ) both impact on the oxidising power of the troposphere.

The rate of (R3) is determined by the available aerosol surface area and the efficiency of the trace-gas aerosol interaction, the latter being described by the uptake coefficient, $\gamma$. Using values of $\gamma$ of $\approx 0.1$, early modelling studies established an important role for reaction (R3) on aqueous surfaces (Dentener and Crutzen, 1993) though the effect is still significant with the presently preferred values of $\gamma$ which are closer to 0.02 (Evans and Jacob, 2005).

In the absence of experimental data on the efficiency of uptake of $\mathrm{N}_{2} \mathrm{O}_{5}$ to a mineral dust surface, previous efforts to model the effect of this process have used values of $\gamma$ which reveal a large spread: Dentener et al. (1996) used $\gamma=0.1$ based on the data available for aqueous surfaces at that time whilst Zhang et al. (1994) allowed $\gamma$ to vary between 0.01 and 1. More recently, values of $\gamma=0.03,0.01$ and 0.001 have been used by Shon et al. (2004), Evans and Jacob (2005) and Bian and Zender (2003), respectively. Bauer et al. (2004) employed a value of $\gamma$ that varied between 0.02 and 0.003 depending on relative humidity.

Experimental data which has been published since these modelling studies does not help to resolve the issue, as two separate studies using essentially the same experimental method, and both using Saharan dust samples have derived values of the uptake coefficient as diverse as 0.01 (Seisel et al., 2005) and 0.2. (Karagulian et al., 2006) Both Seisel et al. (2005) and Karagulian et al. (2006) carried out experiments using porous, bulk substrates and Knudsen reactors, which can lead to large uncertainty in estimation of the surface area available for reaction and which do not allow variation of relative humidity. In order to overcome the limitations posed by the Knudsen reactor approach we have conducted experiments using an aerosol flow reactor with dispersed, authentic Saharan dust from the Cape Verde islands (SDCV). In addition to removing the problems associated with the use of bulk samples, this approach also enabled experiments to be conducted under different relative humidities. We compare our results using the aerosol flow reactor to our Knudsen reactor experiments using SDCV, Arizona test dust (ATD), and calcite $\left(\mathrm{CaCO}_{3}\right)$, and to the two previous literature values.

\section{Experimental section}

Two distinctly different set ups have been used to investigate the interaction of $\mathrm{N}_{2} \mathrm{O}_{5}$ with mineral dust. Similar to our previous work on $\mathrm{HNO}_{3}$ (Hanisch and Crowley, 2001b), we used a Knudsen reactor to investigate the uptake to bulk samples under conditions of low humidity, whilst uptake to airborne mineral aerosol was investigated using an aerosol flow tube, both operated at the laboratory temperature of $296 \pm 2 \mathrm{~K}$. The aerosol flow tube is described here for the first time so a detailed technical description is given. The Knudsen reactor has been described previously (Hanisch and Crowley, 2001b) and only salient features and operational parameters are mentioned here.

\subsection{Aerosol flow tube}

\subsubsection{Gas flow characteristics}

The aerosol flow tube (AFT, Fig. 1) is a vertically mounted Pyrex tube of length $120 \mathrm{~cm}$ and internal diameter $4 \mathrm{~cm}$. Aerosol can be introduced into the top of the AFT via a side arm, whereas trace gases are introduced axially into the centre of the AFT via a stainless steel, movable injector ( $6 \mathrm{~mm} \mathrm{OD})$, the position of which defines the contact time between trace gases and aerosol or reactor walls. $\mathrm{N}_{2} \mathrm{O}_{5}$ is flown through the stainless steel injector through a $1 / 8$ th inch Teflon pipe and only has contact with the last $10 \mathrm{~cm}$ of the injector, which is coated with a thin Teflon film (Dupont, FEP). The AFT is usually operated at or close to atmospheric pressure to reduce loss of $\mathrm{N}_{2} \mathrm{O}_{5}$ to the walls, which, combined with total gas flows of $3 \mathrm{~L}$ (STD) $\mathrm{min}^{-1}$ (SLM) $\mathrm{N}_{2}$ result in a Reynolds number of 110 and an entrance length to acquire laminar flow of $\approx 25 \mathrm{~cm}$.

Most experiments were carried out using an aerodynamic particle sizer (see below) which operates at a flow of 5 SLM, 


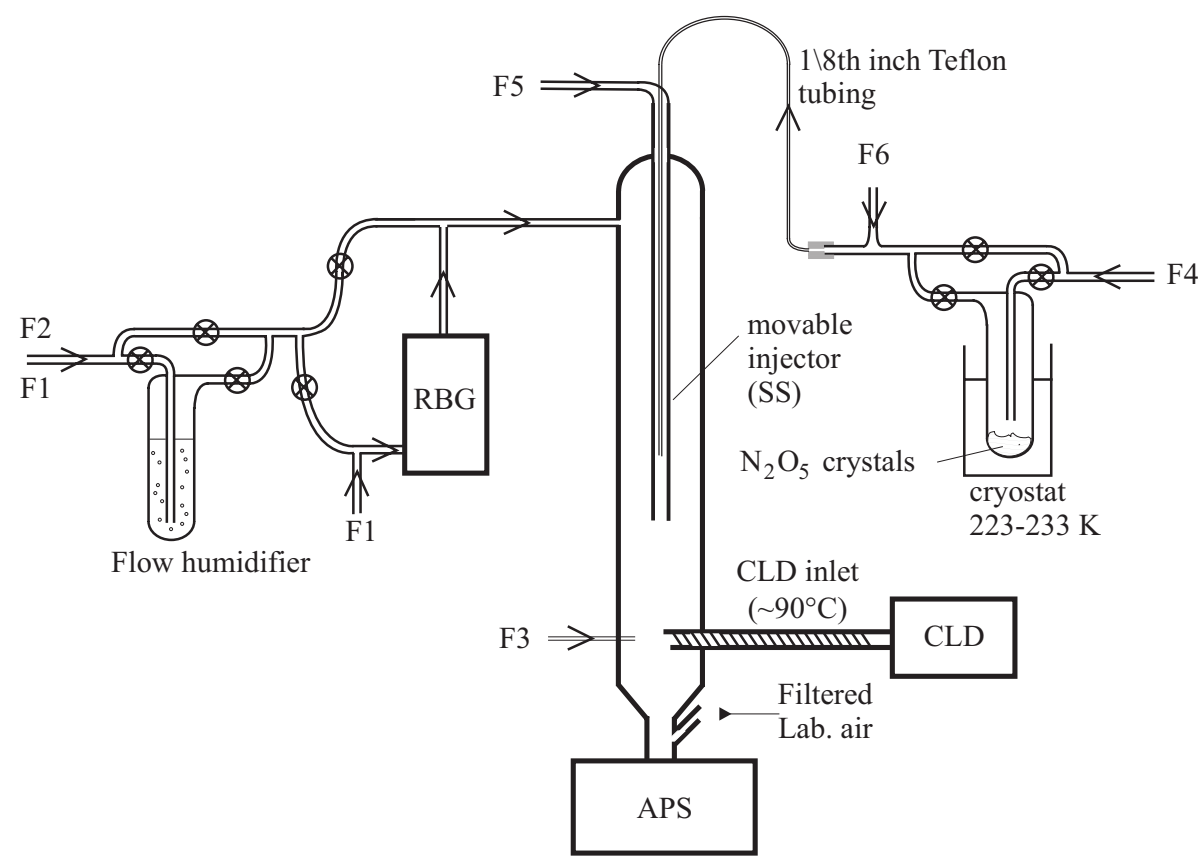

Fig. 1. Aerosol flow tube set-up. RBG = rotating brush generator, $\mathrm{CLD}=$ chemiluminescence NO detector, APS = aerodynamic particle sizer spectrometer, $\mathrm{SS}=$ stainless steel. The total flow $\left(\mathrm{N}_{2}\right.$ unless otherwise stated) was $3000 \mathrm{sccm}$ with (typically) F4+F6=500 sccm; F5=10 sccm; $\mathrm{F} 3=20 \mathrm{sccm}\left(0.001 \% \mathrm{NO}\right.$ in $\left.\mathrm{N}_{2}\right) ; \mathrm{F} 1+\mathrm{F}_{2}=2500 \mathrm{sccm}$ (with a variable proportion through the humidifier to obtain $\mathrm{RH}$ of 0,29 and $\left.58 \%\right)$.

so that an addition 2 SLM of filtered (particle free) laboratory air, was mixed into the 3 SLM reactor flow downstream of the reactor (see Fig. 1). The total reactor flow comprised of 2.5 SLM carrying the aerosol (partly passing through the aerosol generator (see below) and partly passing through a bubbler containing water for humidification of the flow) and 0.5 SLM via the injector. By variation of the flow through the bubbler, the experimental relative humidity $(\mathrm{RH})$ was set at 0,29 or $58 \%$. Other minor flows e.g. $10 \mathrm{~cm}^{3}$ (STD) $\mathrm{min}^{-1}$ $(\mathrm{sccm})$ injector purge are indicated in Fig. 1.

Mixing of trace gas flowing from the injector with the bulk flow was observed by adding $\mathrm{NO}_{2}$ to the injector and measuring its concentration at various fixed distances from the inlet to the detector (see below). Well mixed flows were observed at distances greater than $\approx 25 \mathrm{~cm}$ from the injector. At 3 SLM total flow rate the average linear velocity was $\approx 4 \mathrm{~cm} \mathrm{~s}^{-1}$, resulting in a maximum trace gas residence time of $\approx 30 \mathrm{~s}$. The validity of calculating the average velocity via total flow rates and pressure could be confirmed by adding a pulse of gas $\left(\mathrm{NO}_{2}\right)$ to the injector and monitoring its average time of arrival at the detector.

\subsubsection{Generation and detection of $\mathrm{N}_{2} \mathrm{O}_{5}$}

$\mathrm{N}_{2} \mathrm{O}_{5}$ was eluted via the injector into the flow tube by passing a stream of $\mathrm{N}_{2}$ (usually $20-80 \mathrm{sccm}, \mathrm{F} 4$ ) over $\mathrm{N}_{2} \mathrm{O}_{5}$ crystals held at $223 \mathrm{~K}$ and dynamically diluting this flow with further $480-420 \mathrm{sccm} \mathrm{N}_{2}$ (F6). The complete injector flow $(500 \mathrm{sccm})$ was transported through $1 / 8$ th inch Teflon piping $(\approx 1.5 \mathrm{~m})$ into the lower $10 \mathrm{~cm}$ of the injector (i.d. $5 \mathrm{~mm}$ ) and then into the flow tube. The vapour pressure of $\mathrm{N}_{2} \mathrm{O}_{5}$ at $223 \mathrm{~K}$ is $\approx 0.25$ Torr (Fahey et al., 1985) which, assuming saturation of the $\mathrm{N}_{2}$ flow, results in $\mathrm{N}_{2} \mathrm{O}_{5}$ concentrations in the injector of $\approx 10^{13}-10^{14}$ molecule $\mathrm{cm}^{3}$. Mixing of the injector flow $(500 \mathrm{sccm})$ with the main gas flow (2.5 SLM) results in flow tube concentrations of $\mathrm{N}_{2} \mathrm{O}_{5}$ between $5 \times 10^{12}$ and $5 \times 10^{13}$ molecule $\mathrm{cm}^{-3}$, which were necessary for reasons related to the $\mathrm{N}_{2} \mathrm{O}_{5}$ detection scheme (see below). As shown by Reactions (R2) and (R-2), $\mathrm{N}_{2} \mathrm{O}_{5}$ is in dynamic equilibrium with $\mathrm{NO}_{2}$ and $\mathrm{NO}_{3}$, thus the $\mathrm{N}_{2} \mathrm{O}_{5}$ source will also contain these "impurities". Using evaluated (Sander et al., 2006) equilibrium constants and rate coefficients for (R2) and (R-2) it is easy to show that at $223 \mathrm{~K}$ (the temperature of the $\mathrm{N}_{2} \mathrm{O}_{5}$ crystals) the equilibrium favours $\mathrm{N}_{2} \mathrm{O}_{5}$ formation so that its concentration is a factor $\approx 10^{6}$ greater than $\mathrm{NO}_{3}$ and $\mathrm{NO}_{2}$. However, during transport through the injector the gas is warmed to room temperature and $\mathrm{N}_{2} \mathrm{O}_{5}$ (initially at $\approx 10^{14}$ molecule $\mathrm{cm}^{-3}$ ) decomposes to generate $\mathrm{NO}_{3}$ and $\mathrm{NO}_{2}$ at $\approx 1 \%$ level in $\approx 1 \mathrm{~s}$. Dilution in the main flow results e.g. in a concentration of $\mathrm{N}_{2} \mathrm{O}_{5}$ close to $1 \times 10^{13}$ molecule $\mathrm{cm}^{-3}$ and equilibrium concentrations of $\mathrm{NO}_{3}$ and $\mathrm{NO}_{2}$ of $5 \times 10^{11}$ molecule $\mathrm{cm}^{3}$, equilibrium being achieved in $\approx 2 \mathrm{~s}$. The presence of $\mathrm{NO}_{2}$ and $\mathrm{NO}_{3}$ impurities in the flow tube at these low levels has no significant impact on $\mathrm{N}_{2} \mathrm{O}_{5}$ detection, though we later discuss the potential role which the dynamic equilibrium between $\mathrm{N}_{2} \mathrm{O}_{5}$, $\mathrm{NO}_{3}$ and $\mathrm{NO}_{2}$ may have on the determination of $\mathrm{N}_{2} \mathrm{O}_{5}$ loss rates. 
$\mathrm{N}_{2} \mathrm{O}_{5}$ was detected using a modified chemiluminescence detector (CLD). Conventionally, CLD devices are used to detect $\mathrm{NO}_{\mathrm{y}}$ and $\mathrm{NO}_{\mathrm{x}}$ via thermal conversion (in an oven at several hundred ${ }^{\circ} \mathrm{C}$ ) to $\mathrm{NO}$, which is detected via the generation of chemiluminescence $\left(\mathrm{NO}_{2} *\right.$ emission) from its reaction with $\mathrm{O}_{3}$. To detect $\mathrm{N}_{2} \mathrm{O}_{5}$ selectively in the presence of potential impurities such as $\mathrm{NO}_{2}$ and $\mathrm{HNO}_{3}$ we make use of the fact that $\mathrm{N}_{2} \mathrm{O}_{5}$ is thermally unstable and dissociates to $\mathrm{NO}_{3}$ and $\mathrm{NO}_{2}$ rapidly at temperatures well below $100^{\circ} \mathrm{C}$ whereas $\mathrm{HNO}_{3}$ and $\mathrm{NO}_{2}$ do not. At $90^{\circ} \mathrm{C}$ and atmospheric pressure, the lifetime of $\mathrm{N}_{2} \mathrm{O}_{5}$ with respect to thermal dissociation is $\approx 5 \times 10^{-2} \mathrm{~s}$ and the $\mathrm{NO}_{3}$ product of the thermal dissociation reacts rapidly with NO $\left(k_{4}(363 \mathrm{~K})=2.4 \times 10^{-11} \mathrm{~cm}^{3}\right.$ molecule ${ }^{-1} \mathrm{~s}^{1}$ (Sander et al., 2006)):

$\mathrm{NO}_{3}+\mathrm{NO} \rightarrow 2 \mathrm{NO}_{2}$

The inlet to the CLD (see Fig. 1) consisted of a heated length $(\approx 10 \mathrm{~cm})$ of $5 \mathrm{~mm}$ i.d. Teflon tubing (at $90^{\circ} \mathrm{C}$ ) to thermally dissociate $\mathrm{N}_{2} \mathrm{O}_{5}$ and a flow of $\mathrm{NO}$ which could be monitored directly by the CLD (i.e. without the oven). NO was introduced using 1/8th inch stainless steel piping close to the inlet as shown in Fig. 1.

$\mathrm{N}_{2} \mathrm{O}_{5}$ was thus monitored as the change in NO concentration at the detector. $120 \mathrm{sccm}$ of gas were sampled into the heated Teflon tube, resulting in residence times of about $1 \mathrm{~s}$. This residence time, during which all $\mathrm{N}_{2} \mathrm{O}_{5}$ should decompose (R-2) and all $\mathrm{NO}_{3}$ should react with $\mathrm{NO}$, placed some constraint on the lower bound to the concentrations of $\mathrm{NO}$ and $\mathrm{N}_{2} \mathrm{O}_{5}$ which could be used. Also, it was desirable to convert $\mathrm{N}_{2} \mathrm{O}_{5}$ as rapidly as possible to minimise reactions on surfaces that, during an experiment, could change their reactivity towards $\mathrm{N}_{2} \mathrm{O}_{5}$ due to the deposition of mineral aerosol. Numerical simulation of Reactions (R2), (R2) and (R4) at $90^{\circ} \mathrm{C}$ showed that concentrations close to $10^{13}$ molecule $\mathrm{cm}^{-3}$ of $\mathrm{N}_{2} \mathrm{O}_{5}$ and $[\mathrm{NO}] /\left[\mathrm{N}_{2} \mathrm{O}_{5}\right]=1.1$ resulted in a $\mathrm{NO}$ response that equalled the initial $\mathrm{N}_{2} \mathrm{O}_{5}$ concentration and which took place in just $2-3 \mathrm{~cm}$ (i.e. within $0.3 \mathrm{~s}$ ) of the heated Teflon inlet. By calibration of the CLD using a known $\mathrm{NO}$ concentration we thus measured the $\mathrm{N}_{2} \mathrm{O}_{5}$ concentration with $\approx 10 \%$ accuracy.

The large conversion rate of $\mathrm{NO}_{3}$ to $\mathrm{NO}_{2}$ via (R4) also minimises potential loss of $\mathrm{NO}_{3}$ via its thermal dissociation to $\mathrm{NO}$ and $\mathrm{O}_{2}$ (R5), which has been reported to proceed with a time constant of $\approx 7 \mathrm{~s}$ at $90^{\circ} \mathrm{C}$ (Wayne et al., 1991).

$\mathrm{NO}_{3}+\mathrm{M} \rightarrow \mathrm{NO}+\mathrm{O}_{2}+\mathrm{M}$

Experimental tests of the detector set-up, including linearity of response to NO, the lack of NO modulation by added $\mathrm{N}_{2} \mathrm{O}_{5}$ when the heater was cold (confirming the low, (i.e. $5 \%$ ) equilibrium concentrations of $\mathrm{NO}_{3}$ at room temperature as described above) and lack of detector response to $\mathrm{N}_{2} \mathrm{O}_{5}$ in the absence of added NO confirmed the suitability of this approach. In addition, variation of the inlet temperature whilst monitoring a constant concentration of $\mathrm{N}_{2} \mathrm{O}_{5}$ confirmed that $90^{\circ} \mathrm{C}$ was the optimal operational temperature.

\subsubsection{Generation and characterisation of mineral aerosol}

Mineral dust was available in the form of bulk samples of Saharan dust (SDCV), the mineralogy/composition of which have been described in our previous publications (Hanisch and Crowley, 2001a; Hanisch and Crowley, 2001b; Hanisch and Crowley, 2003b; Hanisch and Crowley, 2003a) and is not repeated here. SDCV samples were dispersed and entrained in $\mathrm{N}_{2}$ using a commercial rotating brush generator (Palas, RBG). Using the RBG we were able to produce gas flows containing up to several thousand particles per $\mathrm{cm}^{3}$ in the flow tube, providing sufficient surface area for $\mathrm{N}_{2} \mathrm{O}_{5}$ uptake and reaction on the $\approx 10-30$ s time scale of the experiments. An aerosol impactor located close to the output of the RBG removed particles of diameters greater than a few $\mu \mathrm{m}$.

The number and size distribution of particles in the reactor was monitored using a aerodynamic particle sizer spectrometer, APS (TSI-3321), located downstream of the flow tube and which sampled the complete 3 SLM flow (and an additional 2 SLM of lab air, containing no particles in that size range, see above). The APS measures particles in the size range 0.5 to $17 \mu \mathrm{m}$ and was thus suitable for the coarse mineral aerosol particles studied in this work. The use of high particle concentrations required employment of a dilution stage (factor 20) in the APS (TSI-3302A). The APS works on the time of flight principle to derive an equivalent aerodynamic particle diameter $\left(D_{a}\right)$, defined as the diameter of a spherical particle of unit density $(\rho)$ with identical aerodynamic properties. The aerodynamic diameter can be corrected for non-unity density to derive the Stokes equivalent diameter (Hinds, 1999) $\left(D_{s}\right)$ which can be used to calculate e.g. the surface area of a spherical particle.

$D_{s}=D_{a} \sqrt{\frac{1}{\rho}}$

The calibration of the APS was tested using spherical Latex particles (provided by TSI) with nominal diameters of 7.24 and $10.98 \mu \mathrm{m}$ which have a density of $1 \mathrm{~g} \mathrm{~cm}^{-3}$, so that $D_{s}=D_{a}$. The APS measured these particles reliably, returning diameters of 7.7 and $11.1 \mu \mathrm{m}$, respectively, a deviation of less than $6 \%$. The accuracy of the APS in the small particle range was tested with spherical $\mathrm{SiO}_{2}$ particles of known diameter (determined by scanning electron microscope). Once corrected for the density of the $\mathrm{SiO}_{2}$ spheres, the APS measured diameters of 430,890 and $1200 \mathrm{~nm}$ for the nominally 500,1000 and $1400 \mathrm{~nm}$ particles, respectively indicating deviations of $10-15 \%$.

A SDCV particle distribution obtained using the APS is given in Fig. 2. The distribution maximises at an aerodynamic diameter of $1.5 \mu \mathrm{m}$, which is in good agreement with an independent analysis using a loaned, electrical low 
pressure impactor (Dekati Ltd.), which measured an aerodynamic diameter of between 1 and $2 \mu \mathrm{m}$. In addition, Inspection by scanning electron microscopy of SDCV particles collected on an impactor from the reactor indicate that nonagglomerated particles indeed have a diameter which is close to $1 \mu \mathrm{m}$.

Once corrected for the SDCV density of $2.7 \mathrm{~g} \mathrm{~cm}^{-3}$ (Hanisch and Crowley, 2003b), the APS data result in a Stokes average diameter of $0.85 \mu \mathrm{m}$. The APS provides both analogue output related to the number of particles per $\mathrm{cm}^{3}$, and also a time averaged size distribution. Typically the size distribution was recorded every $2 \mathrm{~s}$ whilst the number of particles was recorded continuously and over the same time period as the $\mathrm{N}_{2} \mathrm{O}_{5}$ signal was acquired.

At this point we note that the Saharan dust particles used in this study are not spherical. For sedimenting particles, shape correction factors, $\beta$ may be applied to derive the Stokes diameter:

$$
D_{s}=D_{a} \sqrt{\frac{1}{\rho \beta}}
$$

For sedimenting, non spherical quartz particles a shape correction factor of 1.36 has been proposed (Hinds, 1999) which results in a reduction in $D_{s}$ of $\approx 15 \%$. However, it is not clear to what extent this correction can be applied to accelerated SDCV particles in the APS. The accuracy of the APS size distribution and number density was tested by measuring these parameters over a prolonged $(\approx 60 \mathrm{~min})$ flow of SDCV through the instrument and weighing the total dust sample. The dust mass was then compared to that calculated mass based on the APS total number of particles in each size bin and the known density of the dust. The results showed that the true mass (weighed) was $\approx$ a factor $2( \pm 0.3)$ greater than that obtained from the APS, which would translate to an underestimate of the average particle size of $\approx 25 \%$. This value is taken into consideration when we later discuss the experimental data and the calculation of uptake coefficients. In the following text, we cite the Stokes equivalent diameter, $D_{s}$. without correction for particle shape.

We note that the SDCV particle size of close to $1 \mu \mathrm{m}$ measured here is similar to measurements of Saharan dust in the atmosphere, which indicate effective diameters of $1.2-6 \mu \mathrm{m}$ (Immler and Schrems, 2003), or average values of $1.7 \mu \mathrm{m}$ (Meskhidze et al., 2005).

\subsection{Knudsen reactor}

\subsubsection{Reactor parameters}

The Knudsen reactor-mass spectrometer was used in an essentially identical manner as previously reported (Hanisch and Crowley, 2001b). The pressure in the $296 \pm 2 \mathrm{~K}$, Teflon coated Knudsen cell was varied between 0.08 and 0.13 mTorr with the concentration of $\mathrm{N}_{2} \mathrm{O}_{5}$ varied between $3 \times 10^{9}$ and $2 \times 10^{10}$ molecule $\mathrm{cm}^{3}$. In the present experiments, only the

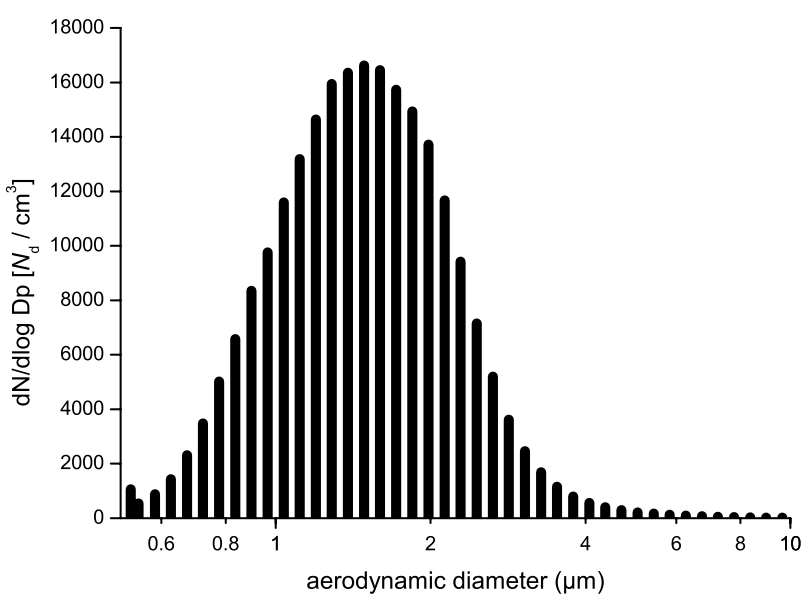

Fig. 2. Size distribution of SDCV as measured by the aerodynamic particle sizer spectrometer. Note that no particles were observed out to $17 \mu \mathrm{m}$, the end of the APS measurement range.

$10.0 \mathrm{~mm}$ escape orifice was used. The mineral samples were prepared by mixing into a paste with methanol and dispersed to form even films on polished $\alpha-\mathrm{Al}_{2} \mathrm{O}_{3}$ (1120) crystals, which were shown to have no observable reactivity towards $\mathrm{N}_{2} \mathrm{O}_{5}$. The films, of geometric surface area $1.0 \mathrm{~cm}^{2}$, were heated to $400 \mathrm{~K}$ for $5 \mathrm{~h}$ under vacuum before allowing to cool to room temperature for an experiment. Alternatively, they were allowed to dry in the sample compartment at room temperature under vacuum for $8 \mathrm{~h}$. The mass of the dust on the $\alpha-\mathrm{Al}_{2} \mathrm{O}_{3}$ crystal was obtained by weighing after the experiment.

Gas phase $\mathrm{N}_{2} \mathrm{O}_{5}$ was introduced into the reactor in a small flow of dried $\mathrm{N}_{2}$ passed over $\mathrm{N}_{2} \mathrm{O}_{5}$-crystals held in a vessel at temperatures of between 208 and $203 \mathrm{~K}$. The $\mathrm{N}_{2} \mathrm{O}_{5}$ concentration, typically $<1 \times 10^{10}$ molecule $\mathrm{cm}^{-3}$, was calculated assuming saturation of the gas flowing over the $\mathrm{N}_{2} \mathrm{O}_{5}$.

$\mathrm{N}_{2} \mathrm{O}_{5}$ was monitored by the $\mathrm{NO}_{2}^{+}$fragment at $m / z=46$. It was therefore important to establish that $\mathrm{HNO}_{3}$ impurity was reduced as far as possible, as $\mathrm{HNO}_{3}$ also fragments to $m / z=46$. For this reason, the $\mathrm{HNO}_{3}$ parent ion at $m / z=63$ was also recorded enabling correction of $\mathrm{N}_{2} \mathrm{O}_{5}$ concentrations. As the $\mathrm{HNO}_{3}$ concentration (obtained by comparison with calibration mixtures of $\mathrm{HNO}_{3}$ ) (Hanisch and Crowley, 2001b) was $<5 \%$ that of $\mathrm{N}_{2} \mathrm{O}_{5}$, this correction was small and had no significant impact on measurements of the uptake coefficient.

\subsection{Chemicals/dust samples}

$\mathrm{N}_{2} \mathrm{O}_{5}$ was prepared by mixing dried flows of $\mathrm{NO}_{2}(99.5 \%)$ and $\mathrm{O}_{3}$ in $\mathrm{O}_{2}$ at room temperature and trapping the product in a cold finger held at $195 \mathrm{~K}$. The reaction time was kept at $\approx 1$ min, which, combined with large $\mathrm{O}_{3}$ concentrations ensured that all $\mathrm{NO}_{2}$ was oxidised. This was checked by visually inspecting the complete disappearance of the brown 


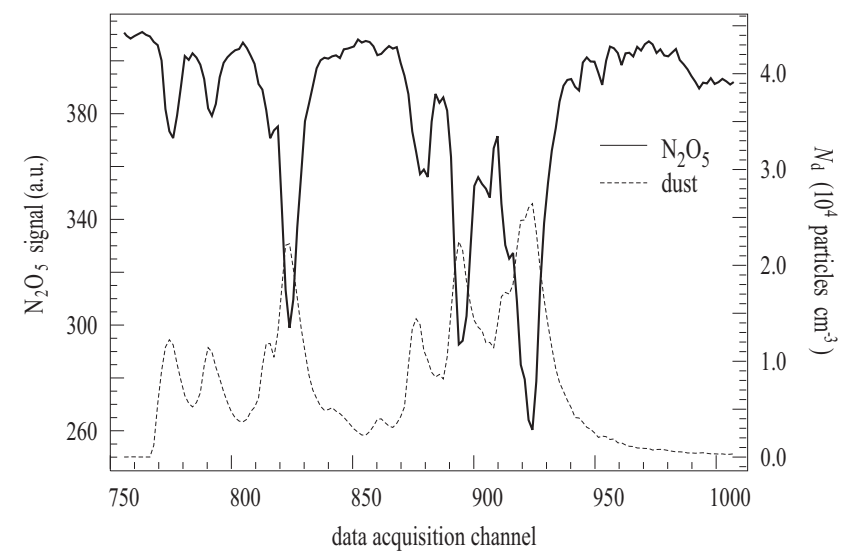

Fig. 3. Response of $\mathrm{N}_{2} \mathrm{O}_{5}$ (solid line, left y-axis) to the addition of a mineral dust pulse (dotted line, right y-axis) to the flow reactor. The time between acquisition of neighbouring data points was $\approx 1.7 \mathrm{~s}$.

colour of $\mathrm{NO}_{2}$ gas within a few seconds of mixing. At the prevailing concentrations, neither $\mathrm{O}_{2}$ nor $\mathrm{O}_{3}$ condense at $195 \mathrm{~K}$, so that only $\mathrm{N}_{2} \mathrm{O}_{5}$ crystals should be present in the trap. The $\mathrm{N}_{2} \mathrm{O}_{5}$ crystals were stored at $223 \mathrm{~K}$ in a darkened vessel. The major impurity was found by mass spectrometry to be $\mathrm{HNO}_{3}$, which arises via reaction of $\mathrm{N}_{2} \mathrm{O}_{5}$ with surface bound water.

$\mathrm{O}_{3}$ was prepared by passing $\mathrm{O}_{2}$ (Westfalen, 5.0) through a commercial ozoniser, $\mathrm{NO}_{2}$ (Aldrich, $>99.5 \%$ ) was used as provided. Anhydrous $\mathrm{HNO}_{3}$ was generated by slowly mixing $\mathrm{KNO}_{3}$ and $\mathrm{H}_{2} \mathrm{SO}_{4}$ at $273 \mathrm{~K}$ and trapping the $\mathrm{HNO}_{3}$ vapour at $77 \mathrm{~K}$. Liquid samples of pure $\mathrm{HNO}_{3}$ were stored in darkened glass fingers at $233 \mathrm{~K} . \mathrm{N}_{2}$ used for the main experimental flow Westfalen 5.0) was used as provided.

The Saharan dust used in these experiments (kindly provided by Laurent Gomes) originates from the Cape Verde Islands (SDCV). Its mineralogy is similar to that described by (Chester and Johnson (1971), its composition, as determined by energy dispersive $\mathrm{X}$-ray spectroscopy, was reported previously (Hanisch and Crowley, 2003b). The Arizona test dust used was a commercial source (Powder technology Inc. MN, USA) of ground Arizona desert sand.

Calcite $\left(\mathrm{CaCO}_{3}\right)$ is an important component that is present in mineral dust at varying concentrations. The northern part of the Sahara is a region enriched by carbonate soils (Gomes and Gillette, 1993) and Saharan dust consists of 5-30\% calcite (Loyë-Pilot et al., 1986; Levin et al., 1990). Desert particles from China contain $\mathrm{CaCO}_{3}$ with a weight fraction of 10-20\% (Okada et al., 1987; Matsuki et al., 2005). Our synthetic $\mathrm{CaCO}_{3}$ samples were provided by Aldrich-Sigma.

\section{Results and discussion}

\subsection{Aerosol flow tube experiments}

The aerosol flow tube was primarily used to examine the uptake of $\mathrm{N}_{2} \mathrm{O}_{5}$ to entrained mineral dust samples, the procedures and data analysis are described in Sect. 3.1.1. A small set of experiments were also carried out in the absence of aerosol to establish the reactivity of $\mathrm{N}_{2} \mathrm{O}_{5}$ at the reactor wall and to determine the diffusion coefficient of $\mathrm{N}_{2} \mathrm{O}_{5}$ in $\mathrm{N}_{2}$ (Sect. 3.1.2).

\subsubsection{Uptake of $\mathrm{N}_{2} \mathrm{O}_{5}$ to airborne mineral dust}

Despite efforts to provide a stable supply of aerosol to the reactor, the measured particle density showed large fluctuations on a timescale of a few seconds. For this reason, the experiments were always conducted using short bursts (100 s of seconds) of dust into the reactor to observe the response of $\mathrm{N}_{2} \mathrm{O}_{5}$. A typical data set is displayed in Fig. 3. The striking anti-correlation between the $\mathrm{N}_{2} \mathrm{O}_{5}$ signal (initial concentration was $5 \times 10^{12}$ molecule $\left.\mathrm{cm}^{-3}\right)$, with small variations of $N_{d}$ (number of dust particles $\mathrm{cm}^{-3}$ ) shows that $\mathrm{N}_{2} \mathrm{O}_{5}$ is taken up to the dust surface.

In this plot, the dust number density is derived from the analogue output of the APS, and is measured with the same time step (integration time) as the $\mathrm{N}_{2} \mathrm{O}_{5}$ signal. Due to transport from the reactor to the CLD the signal due to $\mathrm{N}_{2} \mathrm{O}_{5}$ is shifted $\approx 1 \mathrm{~s}$ later than the dust measurement. This time delay has been corrected in Fig. 3 and for all data sets.

The change of concentration $([c])$ of a trace gas due to uptake to a surface is given by:

$k_{\mathrm{obs}}=\frac{d[c]}{d t \cdot[c]}=\frac{\gamma \cdot \bar{c}}{4} \cdot \frac{a}{V}$

where a is the surface area $\left(\mathrm{cm}^{2}\right), V$ is the volume $\left(\mathrm{cm}^{3}\right)$ and $\bar{c}$ is the mean molecular velocity $\left(\mathrm{cm} \mathrm{s}^{-1}\right)$ of the trace gas at the appropriate temperature.

Following integration of Eq. (3) the uptake of $\mathrm{N}_{2} \mathrm{O}_{5}$ to uniformly dispersed dust aerosol under pseudo-first order conditions (number of reactive surface sites not significantly changed during reaction time) may be described by:

$$
-\ln \left(\frac{\left[\mathrm{N}_{2} \mathrm{O}_{5}\right]_{t}}{\left[\mathrm{~N}_{2} \mathrm{O}_{5}\right]_{0}}\right)=k_{d} t+k_{w} t
$$

where $k_{d}$ is the pseudo first order rate coefficient for uptake to dust aerosol $\left(\mathrm{s}^{-1}\right)$ and $k_{w}$ is the wall loss rate coefficient $\left(\mathrm{s}^{-1}\right) . k_{d}$ is thus the gas collision frequency with the dust multiplied by the efficiency of uptake on a per-collision basis, the uptake coefficient, $\gamma$ :

$k_{d}=\frac{\gamma \cdot \bar{c} \cdot A}{4}$

where $A$ is equal to $\mathrm{a} / \mathrm{V}$ and is the surface area of the dust aerosol per volume of gas $\left(\mathrm{cm}^{2} \mathrm{~cm}^{-3}\right)$. The total dust area 


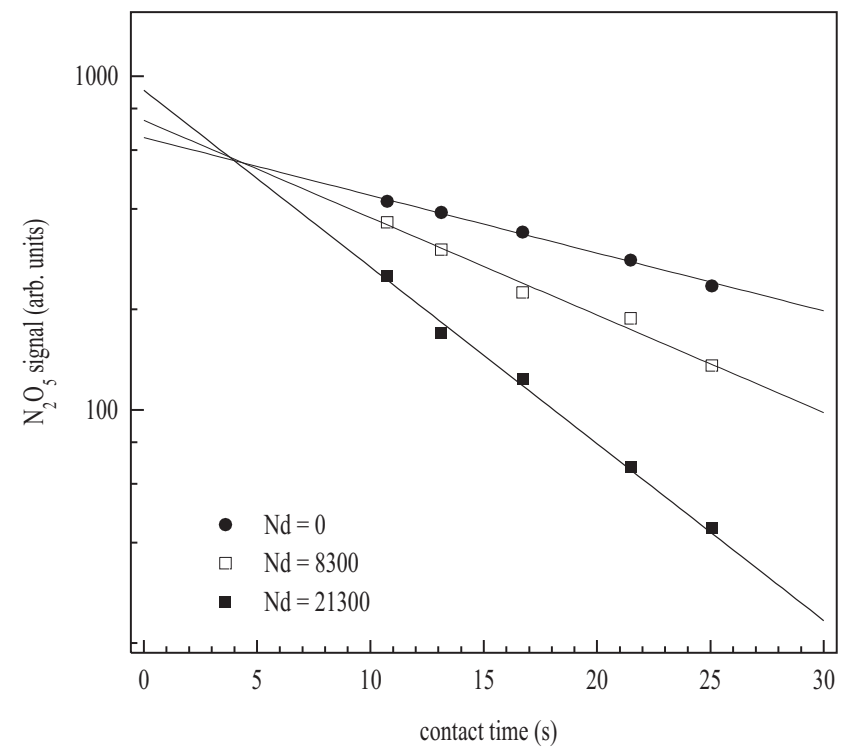

Fig. 4. $\mathrm{N}_{2} \mathrm{O}_{5}$ signal versus contact time for three dust concentrations. $N_{d}$ is the number of dust particles per $\mathrm{cm}^{3}$. The decay of $\mathrm{N}_{2} \mathrm{O}_{5}$ in the absence of aerosol $\left(N_{d}=0\right)$ is due to loss to the reactor wall. Experimentally determined pseudo first-order loss coefficients were: $(4.0 \pm 0.3) \times 10^{-2},(6.7 \pm 1.0) \times 10^{-2}$ and $(12.2 \pm 1.6) \times 10^{-2}$ for $N_{d}=0,8300$ and $21300 \mathrm{~cm}^{-3}$, respectively. The errors quoted are $2 \sigma$ statistical.

$A$, is equal to the product of the number of dust particles per volume $N_{d}\left(\mathrm{~cm}^{-3}\right)$ and the average surface area of a single dust particle $A_{d}$, so that:

$k_{d}=\frac{\gamma \cdot \bar{c} \cdot N_{d} \cdot A_{d}}{4}$

$k_{d}$ is usually derived by combining Eqs. (4) and (5) and plotting the natural $\log$ of the relative $\mathrm{N}_{2} \mathrm{O}_{5}$ concentration versus contact time for a series of dust concentrations as shown in Fig. 4. This analysis requires that the sensitivity of the detector to $\mathrm{N}_{2} \mathrm{O}_{5}$ remains constant as the experiment progresses. This was generally the case, although sometimes a slight loss $(<10 \%)$ of sensitivity was observed after a dust burst. A correction to the $\mathrm{N}_{2} \mathrm{O}_{5}$ signal was applied to take this into account, and was derived by occasionally taking $\mathrm{N}_{2} \mathrm{O}_{5}$ signals at the same injector position in the absence of dust.

The expected exponential dependence of $\left[\mathrm{N}_{2} \mathrm{O}_{5}\right]$ is observed, enabling extraction of $k_{d}$. The common intercept of the three data sets shown at $t \approx 5 \mathrm{~s}$ is due to finite mixing times and entrance lengths to acquire laminar flow (see Experimental section). The observed pseudo first-order decay constants $\left(k_{\text {obs }}\right)$ obtained in the presence of dust were corrected by subtracting the separately measured wall loss rate of $\left(4 \times 10^{-2} \mathrm{~s}^{-1}\right)$ and for axial diffusion (Brown, 1978) to obtain $k_{d}$. The present flow conditions and loss rates resulted in corrections for axial diffusion of less than $10 \%$. We note that as the loss rate of $\mathrm{N}_{2} \mathrm{O}_{5}$ to the wall was close to being diffusion limited in these experiments the value of $k_{w}$ depended

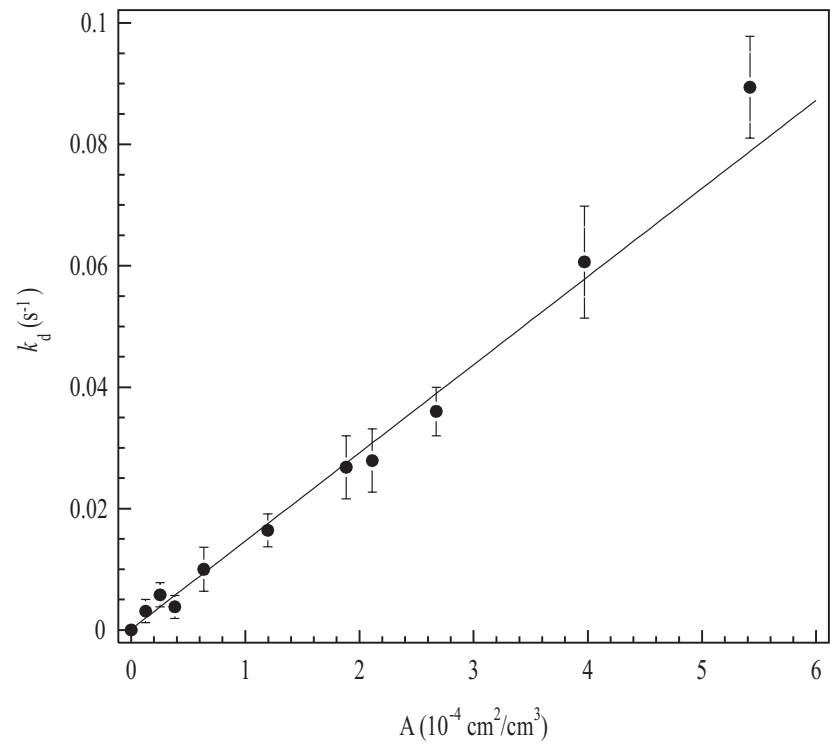

Fig. 5. Dependence of the pseudo first-order decay rate $\left(k_{d}\right)$ of $\mathrm{N}_{2} \mathrm{O}_{5}$ on the dust surface area. The error bars are $1 \sigma$ as obtained from unweighted fitting to data sets similar to those shown in Fig. 4.

strongly on pressure, and only weakly on the state of the wall. Within experimental uncertainty, $k_{w}$ was thus constant with time and dust concentration. This unusual mode of operation with highly reactive walls can be preferential to one in which the rate of uptake of $\mathrm{N}_{2} \mathrm{O}_{5}$ to the wall varies with time due to progressive activation of the wall during an experiment to the take up of dust, which, for SDCV could not be avoided. The large (but constant) wall loss rates must however be less than the rate of uptake to aerosol, which was achieved in the present experiments by using large aerosol surface areas.

By plotting $k_{d}$ versus the dust surface area, $A$, we can derive the uptake coefficient (Eq. 5) as shown in Fig. 5. The dust surface area was obtained from the experimentally determined number density and size distribution which indicated an average (Stokes) particle diameter of $D_{s}=0.9 \mu \mathrm{m}$ for this set of experiments and thus an average particle surface area of $2.54 \times 10^{-8} \mathrm{~cm}^{2}$. The size distribution did not change significantly over the course of an experiment. The error introduced into the dust area calculation by taking the average particle diameter, rather than summed surface area over all size bins was found to be less than $10 \%$ (underestimation) due to the symmetric and relatively narrow distribution. Weighted fitting (Eq. 5) to data in Fig. 5 results in a value of $\gamma_{\text {expt }}=(2.3 \pm 0.3) \times 10^{-2}$.

The rate of uptake of a trace gas to airborne particles can be reduced by concentration gradients close to the particle surface leading to an underestimation of the true uptake coefficient, $\gamma_{\text {true }}$. Generally this effect can be corrected (Fuchs and Sutugin, 1970) using:

$$
\frac{1}{\gamma_{\text {true }}}=\frac{1}{\gamma_{\exp t}}-\frac{0.75+0.283 K n}{K n(K n+1))}
$$




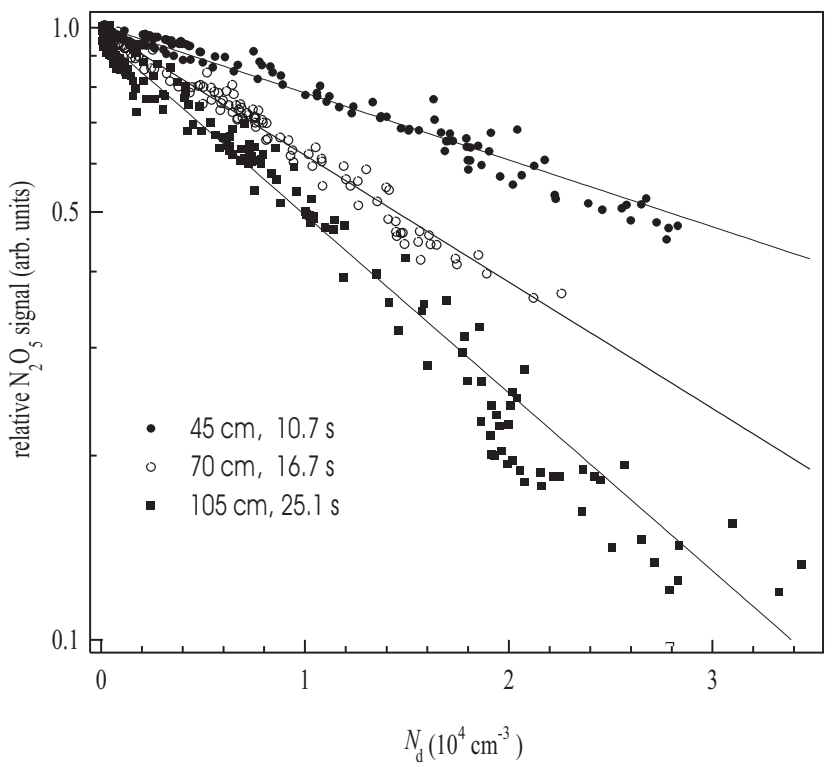

Fig. 6. Dependence of the $\mathrm{N}_{2} \mathrm{O}_{5}$ signal on the dust concentration at three different injector positions. The slope of the exponential fits (solid lines) is equal to $1 / 4 \gamma \bar{c} A_{d} t$. The statistical errors on each single data points are within the symbol size.

where $K n=\frac{3 D_{g}}{\bar{c} \cdot r_{s w}}, D_{g}$ is the gas phase diffusion coefficient of $\mathrm{N}_{2} \mathrm{O}_{5}$ at atmospheric pressure and $296 \mathrm{~K}\left(0.085 \mathrm{~cm}^{2} \mathrm{~s}^{-1}\right.$, see below) and $r_{s w}$ is the radius of the particle at the maximum of the surface area weighted size distribution. The size of the correction is small $(\approx 10 \%)$, so that the final value obtained is $\gamma_{\text {true }}=(2.5 \pm 0.3) \times 10^{-2}$. A more exact analysis, in which the diffusion correction was individually applied to each size bin of the distribution shown in Fig. 2, was carried out for one dataset and resulted in an almost identical correction factor $(\approx 11 \%)$.

This mode of analysis required using data with roughly fixed dust surface areas ( $A$ constant to better than 5\%) from datasets similar to those in Fig. 3, in which the dust was not held constant over a long period of time. Indeed, in such experiments the injector was held fixed whilst the dust concentration was varied, making the task of extracting data with the same value of $A$ but at various injector positions somewhat laborious, and which resulted in non-usage of most of the dataset.

Equations (4) and (5) show that, at any fixed contact time, the relative $\mathrm{N}_{2} \mathrm{O}_{5}$ concentration should display an exponential dependence on the dust number density $\left(N_{d}\right)$. The $\mathrm{N}_{2} \mathrm{O}_{5}$ signal taken directly before each dust pulse was assigned to $\left[\mathrm{N}_{2} \mathrm{O}_{5}\right]_{0}$ and signals taken continuously during the dust pulse to $\left[\mathrm{N}_{2} \mathrm{O}_{5}\right]_{t}$. By taking a new value of $\left[\mathrm{N}_{2} \mathrm{O}_{5}\right]_{0}$ at each injector position, the wall loss of $\mathrm{N}_{2} \mathrm{O}_{5}$ was automatically removed from the dataset. With this method, the complete dataset from each "dust pulse" at each injector position can be used. Such a dataset is displayed in Fig. 6. The expected

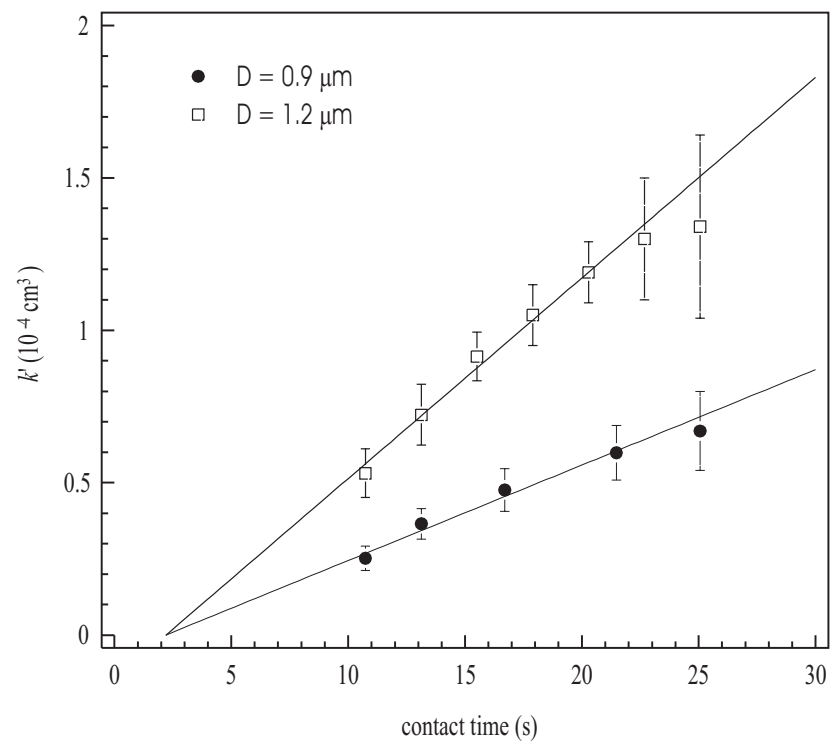

Fig. 7. The slope of the exponential fits to data as shown in Fig. 6 versus contact time for experiments using two different average diameter particle ensembles. The slope, equal to $1 / 4 \gamma \bar{c} A_{d}$, can be used to derive $\gamma$ if the particle diameter (and thus $A_{d}$ ) is known.

dependence of the $\mathrm{N}_{2} \mathrm{O}_{5}$ signal on the dust concentration is observed, the slope is equal to $1 / 4 \gamma \bar{c} A_{d} t$. As the $\mathrm{N}_{2} \mathrm{O}_{5}$ signal was normalised to the initial signal (before dust was introduced), the intercept does not vary with injector position (contact time) as Eq. (3) suggests. For the particular data set displayed in Fig. 6, data were obtained at a total of 5 contact times, $t$, corresponding to injector positions of $35,45,79,90$ and $105 \mathrm{~cm}$. A plot of $1 / 4 \gamma \bar{c} A_{d} t$ versus $t$ is given in Fig. 7 for this data set, and for one further dataset obtained using slightly larger particles (1.2 instead of $0.9 \mu \mathrm{m})$. As expected from Eqs. (4) and (5) the slope of this plot is dependent on the aerosol diameter, and should be equal to $1 / 4 \gamma \bar{c} A_{d}$. As described above, the fact that the term $1 / 4 \gamma \bar{c} A_{d} t$ does not go though zero at $t=0$ is related to an offset in the contact time due to mixing effects. This does however not affect the analysis, which relies on the slope to derive $\gamma$.

Once corrected using Eq. (7), this analysis yields a value for the uptake coefficient of $(2.2 \pm 0.1) \times 10^{-2}$, for the same data set used above to obtain $(2.5 \pm 0.3) \times 10^{-2}$ using the more conventional analysis, and is also in agreement with the value of $(2.7 \pm 0.4) \times 10^{-2}$ derived from the data set displayed in Fig. 7 using larger particles. The good agreement suggests that the approach is sound, and the slight difference in the value of $\gamma$ obtained when using the conventional versus complete analysis is related to the use of different sections of the same dataset. Thus, although the second approach has the advantage that the complete data set can be analysed, it suffers from the disadvantage that the axial diffusion correction (Brown, 1978) is not easy to apply. However, the axial diffusion correction was only $10 \%$ under the flow conditions of 
this study, this is considered negligible compared to errors in the particle surface area (see below).

We note that operating the AFT in "pulsed" mode may result in axial gradients in dust number density, the severity of which depend on the relationship between pulse duration and the flow tube residence time. Axial concentration gradients are not taken care of in the simple steady state analysis used here and may give rise to systematic error. In fact, although there is clear anticorrelation between the dust number density and the $\mathrm{N}_{2} \mathrm{O}_{5}$ concentration, close examination shows that the widths of corresponding features in the dust number density and the $\mathrm{N}_{2} \mathrm{O}_{5}$ concentration are not identical. However, there is no significant and systematic deviation from the expected exponential dependence of the $\mathrm{N}_{2} \mathrm{O}_{5}$ concentration on dust number density even in datasets in which numerous dust features of variable duration (see e.g. Fig. 6) were observed. Although some of the experimental scatter in such datasets may arise because of partial break down of the steady state analysis, this is not the major source of error in these experiments, but might lead to a slight underestimation of the uptake coeffcient.

In total, 20 experiments were carried out using 3 different initial $\mathrm{N}_{2} \mathrm{O}_{5}$ concentrations and 4 different particle diameters. In 12 experiments the gas flow was not humidified $(\mathrm{RH} \approx 0)$, in 4 experiments $\mathrm{RH}$ was set to $29 \%$ and in 4 it was set to $58 \%$. All values of $\gamma_{\text {true }}$ obtained are summarised in Table 1. The errors associated with $\gamma_{\text {true }}$ in the table are derived as described above from a propagation of statistical errors $(2 \sigma)$ in analysing the datasets. The corrections for axial and radial diffusion and for gas transport to the particles (Eq. 7) were only of the order of $10 \%$ and errors associated with these corrections are not considered. The error in the particle concentrations are represented by the scatter of the data points in the plot of Fig. 6 and are thus taken care of in the statistical $2 \sigma$ error. Taking a critical look at our data, the most obvious source of systematic error arises from the surface areas used to calculate $\gamma$. We have calculated the total dust surface area from the average particle diameter from the size distribution and the total number of particles, which results in an underestimation by $\approx 10 \%$. As discussed in the experimental section, a more serious error is related to the conversion of the measured aerodynamic particle diameter to a geometric one, bearing in mind that the particles are non spherical. The effect of irregular particles on the aerodynamic diameter as measured by the APS is difficult to assess, and has been reported to be potentially as large as a factor of two (Hinds, 1999). Our measurements of time-integrated particle mass indicated that the APS may underestimate this parameter by a factor of two, which converts to underestimation of the average diameter by a factor 1.25 , or the surface area by a factor of $\approx 1.6$. In addition, for a given mass, the ratio of surface area of non-spherical to spherical particles varies from 1.24 for a cube, 1.39 for elongated particles with ratio of long to short axis of 3 , to a value of $\approx 1.5$ for a plate shaped particle with the ratio of diameter to depth of 8 . These
Table 1. Aerosol flow tube experiments: Uptake coefficients and experimental conditions.

\begin{tabular}{|c|c|c|c|c|}
\hline $\mathrm{RH}(\%)$ & {$\left[\mathrm{N}_{2} \mathrm{O}_{5}\right]^{\mathrm{a}}$} & $D_{s}(\mu \mathrm{m})$ & $\begin{array}{c}\gamma_{\text {true }} \\
\left(10^{-2}\right)\end{array}$ & $\begin{array}{c}\gamma_{\text {true }}(\text { mean })^{\mathrm{b}} \\
\quad\left(10^{-2}\right)\end{array}$ \\
\hline 0 & 5 & 0.9 & $1.5 \pm 0.3$ & \multirow{12}{*}{$1.3 \pm 0.2$} \\
\hline 0 & 5 & 0.9 & $1.4 \pm 0.3$ & \\
\hline 0 & 6 & 0.9 & $1.7 \pm 0.4$ & \\
\hline 0 & 20 & 0.9 & $1.2 \pm 0.2$ & \\
\hline 0 & 5 & 0.9 & $1.4 \pm 0.3$ & \\
\hline 0 & 5 & 1.2 & $1.7 \pm 0.4$ & \\
\hline 0 & 5 & 1.2 & $1.7 \pm 0.4$ & \\
\hline 0 & 5 & 0.8 & $2.0 \pm 0.4$ & \\
\hline 0 & 5 & 0.9 & $2.0 \pm 0.4$ & \\
\hline 0 & 5 & 0.7 & $0.9 \pm 0.2$ & \\
\hline 0 & 5 & 0.8 & $1.5 \pm 0.4$ & \\
\hline 0 & 5 & 0.7 & $0.9 \pm 0.2$ & \\
\hline 29 & 5 & 0.9 & $1.1 \pm 0.2$ & \multirow{4}{*}{$0.8 \pm 0.2$} \\
\hline 29 & 5 & 0.9 & $0.9 \pm 0.2$ & \\
\hline 29 & 5 & 0.9 & $0.9 \pm 0.2$ & \\
\hline 29 & 20 & 0.9 & $0.6 \pm 0.1$ & \\
\hline 58 & 5 & 0.7 & $0.4 \pm 0.1$ & \multirow{4}{*}{$0.5 \pm 0.1$} \\
\hline 58 & 5 & 0.7 & $0.7 \pm 0.2$ & \\
\hline 58 & 5 & 0.7 & $0.4 \pm 0.1$ & \\
\hline 58 & 5 & 0.8 & $0.7 \pm 0.2$ & \\
\hline
\end{tabular}

${ }^{a}$ Units of $10^{12}$ molecule $\mathrm{cm}^{-3} \cdot \gamma_{\text {true }}$ has been corrected for systematic errors due to diffusion limitation to the uptake and also for errors in measurement of the particle size/shape (see text for details).

$\mathrm{b}$ Weighted average.

considerations lead us to correct our uptake coefficients by a factor of $1.6 \pm 0.2$ obtained from the measurements of integrated particle mass. The values of $\gamma_{\text {true }}$ listed in Table 1 already take this into account. Experimental scatter (probably arising as a result of fluctuations in detector sensitivity during the experiment) is sufficiently large so that a weak dependence in the uptake coefficient on $\left[\mathrm{N}_{2} \mathrm{O}_{5}\right]$ or particle size would remain undetected. The weighted mean values of $\gamma_{\text {true }}$ of $(1.3 \pm 0.2) \times 10^{-2},(0.8 \pm 0.2) \times 10^{-2}$, and $(0.5 \pm 0.1) \times 10^{-2}$ obtained at relative humidities of $0 \%, 29 \%$ and $58 \%$, respectively may indicate some apparent trend, with the lower values obtained at higher relative humidities. Potential reasons for this unexpected trend are discussed later.

A further potential source of error in our measurements is the fact that $\mathrm{N}_{2} \mathrm{O}_{5}$ is accompanied by the products of its thermal dissociation, $\mathrm{NO}_{2}$ and $\mathrm{NO}_{3}$, which are in dynamic equilibrium. Any process (e.g. uptake to dust) that removes $\mathrm{N}_{2} \mathrm{O}_{5}$ from the reactor will result in an adjustment of the equilibrium concentrations of $\mathrm{NO}_{3}$ and $\mathrm{NO}_{2}$ and reformation of $\mathrm{N}_{2} \mathrm{O}_{5}$ via Reaction (R2). The extent of this effect was tested by numerical simulation (Curtis and Sweetenham, 1987). The simulation 


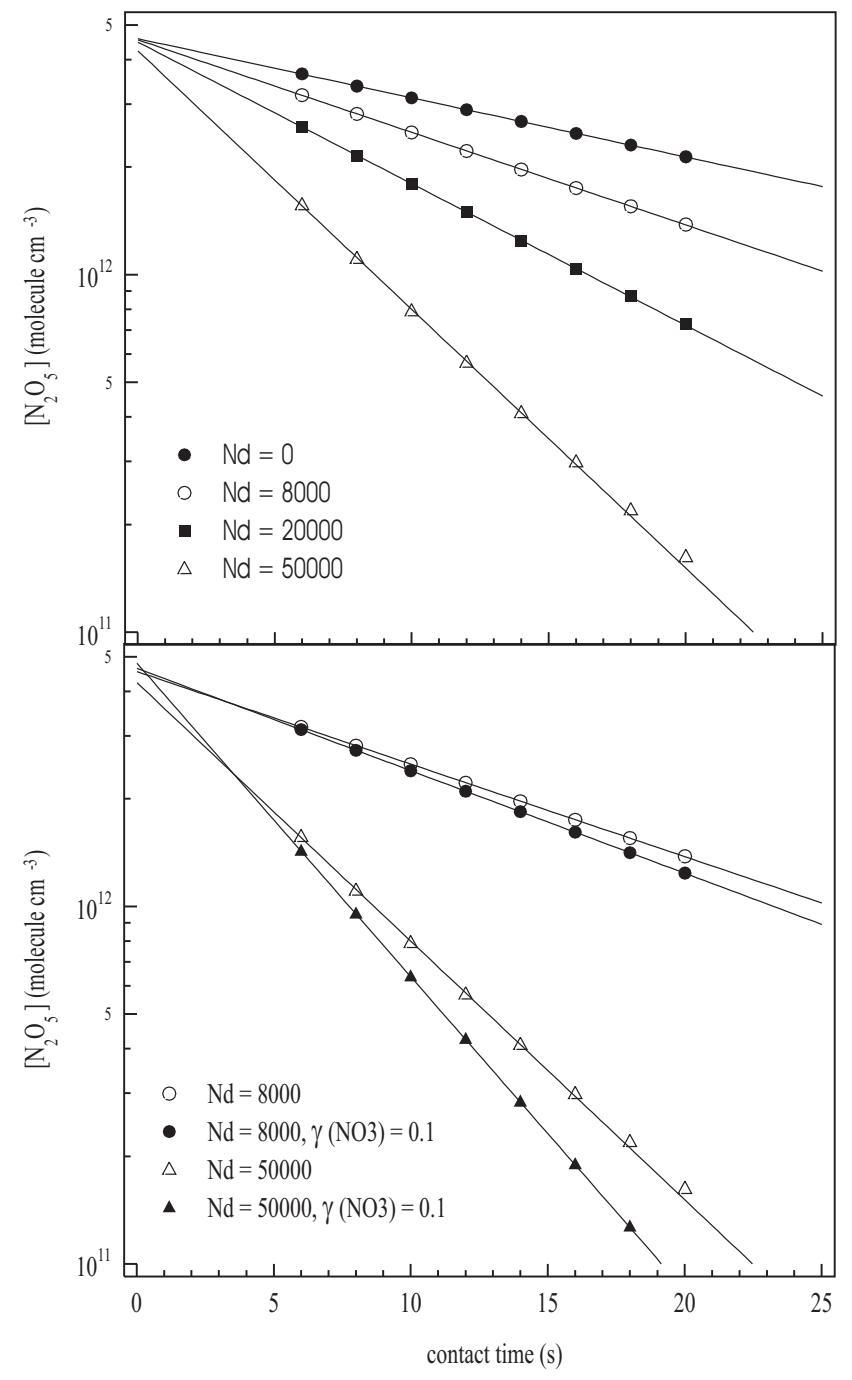

Fig. 8. Simulated $\mathrm{N}_{2} \mathrm{O}_{5}$ profiles, for details see text. Upper panel: Effect of $\mathrm{N}_{2} \mathrm{O}_{5} \Leftrightarrow \mathrm{NO}_{2}+\mathrm{NO}_{3}$ equilibrium on the uptake kinetics of $\mathrm{N}_{2} \mathrm{O}_{5} . \quad N_{d}$ is the dust particle number density $\left(\mathrm{cm}^{-3}\right)$. Lower panel: Effect of $\mathrm{NO}_{3}$ uptake to dust (assuming $\gamma\left(\mathrm{NO}_{3}\right)=0.1$ ) on the $\mathrm{N}_{2} \mathrm{O}_{5}$ profiles. The open symbols are simulations without loss of $\mathrm{NO}_{3}$, the closed symbols represent the effect of $\gamma \mathrm{NO}_{3}=0.1$ with two different dust concentrations.

was initialised with $\left[\mathrm{N}_{2} \mathrm{O}_{5}\right]=5 \times 10^{12}$ molecule $\mathrm{cm}^{-3}$ with $\mathrm{NO}_{3}$ and $\mathrm{NO}_{2}$ at their equilibrium concentration at $296 \mathrm{~K}$ $\left(2.7 \times 10^{11}\right.$ molecule $\left.\mathrm{cm}^{-3}\right)$. Further input parameters were $\gamma_{\text {true }}=2 \times 10^{-2}$ and the particle number density $(0,8000$ or $\left.20000 \mathrm{~cm}^{-3}\right)$ and diameter $(0.9 \mu \mathrm{m})$ and a first order loss rate coefficient of $0.04 \mathrm{~s}^{-1}$ to simulate wall loss. The kinetic parameters for (R2) and (R-2) (the only purely gas phase reactions involved) were taken from an evaluation (Sander et al., 2006).

These parameters were chosen to mimic the real data shown in Fig. 4. The value of $\gamma_{\text {true }}$ was converted in the simulation to a pseudo first-order uptake coefficient using
Eqs. (6) and (7). The results of the simulation are shown in Fig. 8 (upper panel). The simulated profiles (symbols) were fitted to an exponential function to derive the total first order loss coefficient $\left(k_{\mathrm{obs}}\right)$ as carried out for the real experimental data. The results showed that the fitted values of $k_{\text {obs }}$ underestimated the input parameters $\left(k_{w}+k_{d}\right)$ by $5-10 \%$, which is attributed to the regeneration of $\mathrm{N}_{2} \mathrm{O}_{5}$ as described above. This effect can be considered negligible compared to uncertainty in the particle surface area. Close inspection of the simulated data sets (especially at high loss rates for e.g. 50000 particles $\mathrm{cm}^{-3}$ ) showed slight deviation from exponential behaviour for exactly this reason. This would not be detectable in real experimental data with associated noise.

Further, we investigated the impact of the uptake of $\mathrm{NO}_{3}$ to dust, which, via equilibria (R2) and (R-2), could conceivably also change the $\mathrm{N}_{2} \mathrm{O}_{5}$ concentration. A large uptake coefficient for reaction of $\mathrm{NO}_{3}$ with Saharan dust of $\gamma\left(\mathrm{NO}_{3}\right) \approx 0.1$ was recently reported (Karagulian and Rossi, 2005) and we have used this value in our simulation, the results of which are displayed in Fig. 8 (lower panel). The addition of a loss process for $\mathrm{NO}_{3}$ has the expected result of enhancing the $\mathrm{N}_{2} \mathrm{O}_{5}$ loss rate, though the $\mathrm{N}_{2} \mathrm{O}_{5}$ decay remains exponential. The effect on $k_{\mathrm{obs}}$ is however not large $(\approx 10 \%)$. Simulations with larger values of $\gamma\left(\mathrm{NO}_{3}\right)$ do not significantly change this picture as under the present experimental conditions diffusion limitation for uptake to the particles becomes large. The addition of a wall loss for $\mathrm{NO}_{3}$ at approximately twice the rate of $\mathrm{N}_{2} \mathrm{O}_{5}$ wall loss had minimal effect when compared to its uptake to aerosol. In summary, the fact that $\mathrm{N}_{2} \mathrm{O}_{5}$ is not introduced into our reactor as a pure substance but in equilibrium with $\mathrm{NO}_{3}$ and $\mathrm{NO}_{2}$ at the few percent level does not have a significant effect on our analysis of $\mathrm{N}_{2} \mathrm{O}_{5}$ uptake.

\subsubsection{Diffusion coefficient and wall loss of $\mathrm{N}_{2} \mathrm{O}_{5}$}

A series of experiments, all at a total flow rate of 3 SLM and $\left[\mathrm{N}_{2} \mathrm{O}_{5}\right] \approx 2 \times 10^{12}$ molecule $\mathrm{cm}^{-3}$, was carried out to examine the loss of $\mathrm{N}_{2} \mathrm{O}_{5}$ to the walls of the flow tube, whereby no aerosol was entrained in the gas flow but was present on the inner surface of the flow tube in varying, but not controlled amounts.

From Eq. (3), the uptake of a trace gas to a cylindrical surface $\left(a=2 \pi r l\right.$ and $\left.V=\pi r^{2} l\right)$ is given by:

$k_{w}=\frac{\gamma \cdot \bar{c}}{4} \cdot \frac{2}{r}$

where $k_{w}$ is the pseudo first-order loss rate coefficient for wall loss, and $\gamma$ is the uptake coefficent for this process. For the case where the rate of loss of gas is determined not by surface reactivity, but by diffusion through the gas-phase, the following expression holds.

$\gamma_{\mathrm{diff}}=\frac{3.66\left(2 D_{g}\right)}{\bar{c} r}$ 
where $D_{g}$ is the gas phase diffusion coefficient of $\mathrm{N}_{2} \mathrm{O}_{5}$ at the experimental pressure. Combining Eqs. (8) and (9), and rearranging we obtain:

$D_{g}=\frac{k_{w} r^{2}}{3.66}$

Which is valid for Peclet numbers in excess of $\approx 20$ (Zasypkin et al., 1997). The present experimental conditions resulted in Peclet numbers $\left(\mathrm{Pe}=2 r v / D_{g}\right.$, where $v$ is the average linear velocity of the gas flow) of greater than 100 .

By varying the injector position, the pseudo first order loss rate of $\mathrm{N}_{2} \mathrm{O}_{5}$ to the wall $\left(k_{w}\right)$ could be determined at various pressures and converted to values of $D_{g}$ via Eq. (10). This analysis is appropriate if the uptake is irreversible over the time scale of the experiments (i.e. $\mathrm{N}_{2} \mathrm{O}_{5}$ is lost permanently to the wall). For any given injector position, the $\mathrm{N}_{2} \mathrm{O}_{5}$ signal was seen to be invariant with exposure time, confirming that the capacity of the (dusty) walls to take up $\mathrm{N}_{2} \mathrm{O}_{5}$ was sufficiently large. Exponential plots of $\left[\mathrm{N}_{2} \mathrm{O}_{5}\right]$ versus contact time confirm this (Fig. 9 upper panel). Data were analysed at contact times longer than required for laminar flow to establish $(\approx 3 \mathrm{~s}$ at 350 Torr and $\approx 5 \mathrm{~s}$ at 760 Torr $)$.

A linear relationship between $k_{w}$ and pressure showed that at all experimental pressures covered (350 to 750 Torr) the uptake was indeed limited by gas-phase diffusion.

The results of such an experiment are summarised in Fig. 9 (lower panel) which also plots the values of $D_{g}$ obtained via Eq. (10) with previous experimental and theoretical data, most of which present diffusion coefficients at 750-760 Torr. The scatter in the dataset (e.g. at 500 Torr) is larger than that resulting from a rigorous statistical analysis of each data point, and may be a result of non-perfect centring of the injector during translation.

The present data set is entirely consistent with the experimental result of Carstens at 760 Torr (Carstens, 1998), obtained using a completely different approach and also with the various calculated values listed (Monchick and Mason, 1961; Fried et al., 1994; Lovejoy and Hanson, 1995; Hu and Abbatt, 1997) at or close to this pressure. The parameterisation of Monchick and Mason (Monchick and Mason, 1961) also reproduces the observed pressure dependence rather closely. The value we obtained at $296 \mathrm{~K}$ and 760 Torr, $D_{\mathrm{N}_{2} \mathrm{O}_{5}}=0.085 \mathrm{~cm}^{2} \mathrm{~s}^{-1}$, was used in the diffusion corrections reported above.

\subsection{Knudsen reactor experiments}

The Knudsen reactor was used to investigate the uptake of $\mathrm{N}_{2} \mathrm{O}_{5}$ to bulk samples of SDCV, ATD and calcite at $296 \pm 2 \mathrm{~K}$. The effect of changing parameters such as the sample mass (i.e. thickness), the $\mathrm{N}_{2} \mathrm{O}_{5}$ concentration and the heating of the sample under vacuum (drying) were investigated.
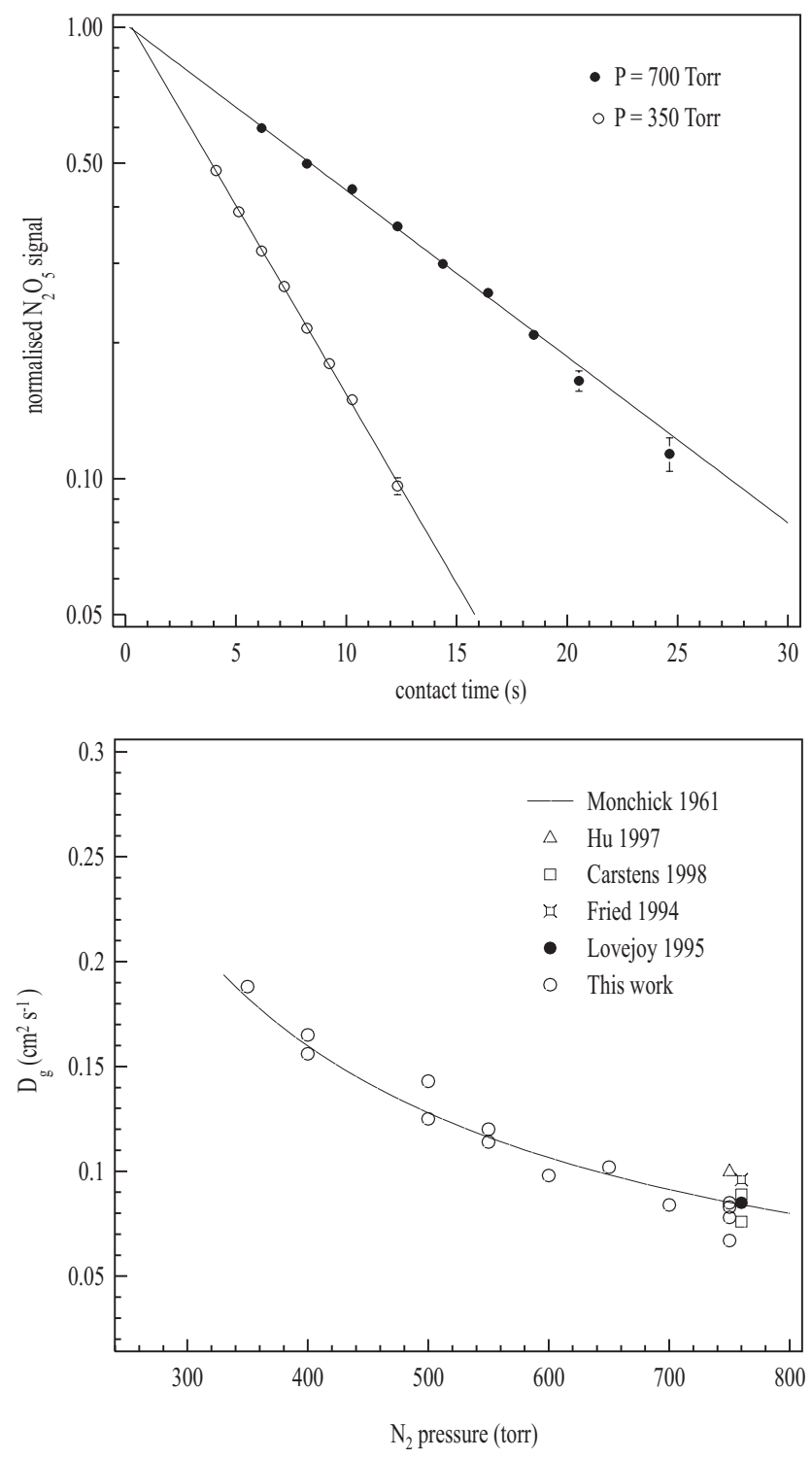

Fig. 9. Upper panel: Exponential decay profiles of $\mathrm{N}_{2} \mathrm{O}_{5}$ due to loss at the reactor wall at experimental pressures of 350 and 700 Torr. The error bars are derived from propagation of errors in the NO difference signal. Lower Panel: Pressure dependent diffusion coefficients from the present study compared to experimental results (Carstens, 1998) and theoretical calculations: $\mathrm{Hu} 1997=\mathrm{Hu}$ and Abbatt (1997), Fried $1994=$ Fried et al. (1994), Monchick $1961=$ Monchick and Mason (1961), Lovejoy $1995=$ Lovejoy and Hanson (1995). For the present data set, statistical errors (from e.g. data sets as shown in the upper panel) were smaller than the symbol size.

\subsubsection{SDCV results}

Data from an experiment in which a bulk SDCV sample (21.6 mg spread onto the $1 \mathrm{~cm}^{2}$ sample holder) was exposed to $\approx 6 \times 10^{9}$ molecule $\mathrm{cm}^{-3}$ of $\mathrm{N}_{2} \mathrm{O}_{5}$ is displayed in Fig. 10 .

Once slight drifts $(<10 \%$ over $30 \mathrm{~min})$ in signal had been removed from the data, correction was made to the raw $\mathrm{N}_{2} \mathrm{O}_{5}$ 


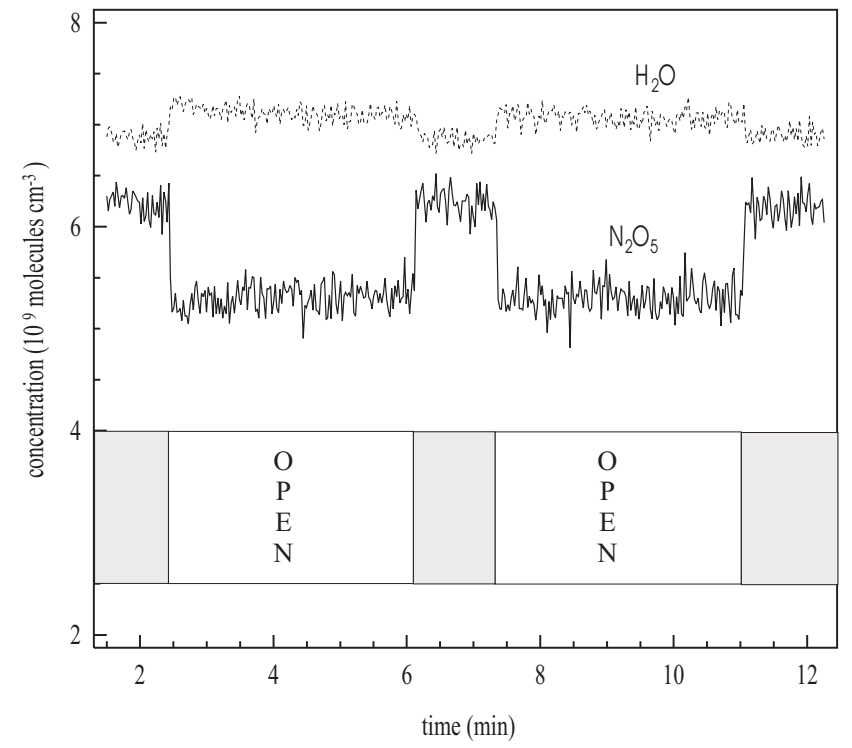

Fig. 10. Knudsen reactor data for the uptake of $\mathrm{N}_{2} \mathrm{O}_{5}$ to $21.6 \mathrm{mg}$ of SDCV. The release of $\mathrm{H}_{2} \mathrm{O}$ from the dust sample upon opening the lid to the sample chamber (multiplied by a factor of 3 for clarity) and the times of opening and closure of the sample chamber (open) are also indicated.

mass spectrometer signal at $m / z=46$ to take into account low levels of $\mathrm{HNO}_{3}$ present in the reactor as evidenced by a weak signal at $m / z=63$.

The weak signal at $m / z=63$ was acquired by integrating for much longer than that at $m / z=46$. As this procedure took several minutes, it was performed before each uptake experiment using the same flow conditions. During non-exposure periods, the $m / z=46$ signal was corrected using the known fragmentation pattern of pure $\mathrm{HNO}_{3}$ samples, whereas during exposure the drop in $\mathrm{HNO}_{3}$ signal was calculated using its uptake coefficient from our previous studies (Hanisch and Crowley, 2001a; Hanisch and Crowley, 2001b), which was then converted to a change in $m / z=46$ due to $\mathrm{HNO}_{3}$. The corrections were in fact very small (only a few percent of the signal due to the low concentration of $\mathrm{HNO}_{3}$ ) and had only minor influence on values of $\gamma$ obtained.

During exposure, the $\mathrm{N}_{2} \mathrm{O}_{5}$ concentration dropped to a steady state value defined by the rate of uptake to the surface and the rates of flow into and escape from the reactor. We have chosen to use a large escape orifice in these experiments in order to avoid concentration gradients at the surface, which can result in the underestimation of the uptake coefficient (see Hanisch and Crowley (2001a, b) for details). Unlike in the AFT experiments, the dust is not replenished during the course of the experiment but can be chemically modified. Due to the low concentrations of $\mathrm{N}_{2} \mathrm{O}_{5}$ used, no significant change in reactivity over a typical exposure period was observed.
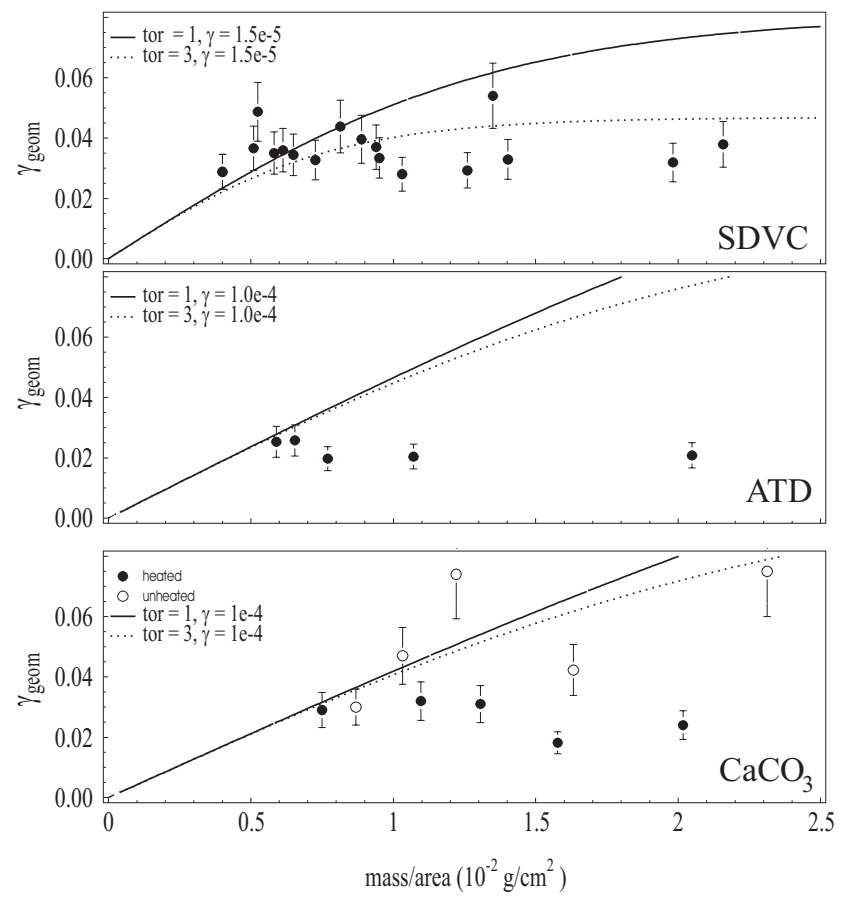

Fig. 11. Uptake coefficients $\left(\gamma_{\text {geom }}\right)$ for interaction of $\mathrm{N}_{2} \mathrm{O}_{5}$ with Saharan dust (SDCV), Arizona test dust (ATD) and calcite. For SDCV and ATD all samples were dried by heating prior to the experiment. For $\mathrm{CaCO}_{3}$ the solid circles indicate uptake coefficients obtained using heated samples. The open circles are data points from unheated samples. The smooth lines represent calculations using a pore diffusion model to take into account the interstitial surface area of the sample. The full line was calculated with a tortuosity factor (tor) of 1 , the dashed line with a value of 3 (see text for details).

As in our previous experiments on $\mathrm{HNO}_{3}$ (Hanisch and Crowley, 2001a; Hanisch and Crowley, 2001b) the uptake coefficient was derived by the difference in trace gas signal when the gas flow was either isolated $\left(S_{0}\right)$ or in contact with the dust sample $\left(S_{d}\right)$. It was not necessary to know the $\mathrm{N}_{2} \mathrm{O}_{5}$ concentration absolutely.

$\gamma_{\mathrm{geom}}=\frac{k_{\mathrm{esc}}}{\omega}\left(\frac{S_{0}}{S_{d}}-1\right)$

where $\gamma_{\text {geom }}$ is the uptake coefficient calculated using the geometric surface area of the sample, $k_{\text {esc }}$ is the escape rate coefficient $\left(10.0 \mathrm{~s}^{-1}\right)$ and $\omega$ is the collision rate with the sample and was calculated from:

$\omega=\frac{\bar{c} A_{g}}{4 V}$

where $A_{g}$ is the projected, geometric surface area of the dust sample $\left(1.0 \mathrm{~cm}^{2}\right), \bar{c}$ is the mean molecular velocity of $\mathrm{N}_{2} \mathrm{O}_{5}$ at $296 \mathrm{~K}$ and $V$ is the volume of the reactor $\left(120 \mathrm{~cm}^{3}\right)$. Values of $\gamma_{\text {geom }}$ obtained by this expression are listed in Table 2 , where the initial $\mathrm{N}_{2} \mathrm{O}_{5}$ concentration and the dust mass are 
also given. As the $\mathrm{N}_{2} \mathrm{O}_{5}$ profile during uptake shows no sign of saturation, the initial uptake $\left(\gamma_{0}\right.$, obtained from the signal drop just after opening the sample holder) is equal to the steady state uptake, $\gamma_{s s}$.

The data, plotted in Fig. 11, are encompassed by the value $\gamma_{\text {geom }}=(3.7 \pm 1.2) \times 10^{-2}$. Three quantities contribute significantly to the total statistical error of $\approx 10 \%$ in these experiments (error bars in Fig. 11): $k_{\text {esc }}$ was determined with an accuracy of $\approx 5 \%$; the error in $\omega$ was estimated as $\approx 5 \%$ due to uncertainty in the coverage of the dust on the $\alpha$ $\mathrm{Al}_{2} \mathrm{O}_{3}$ crystal, which was observed to contract slightly at the edges during the drying procedure. The error in the signal at $m / z=46$ is dependent upon the size of the signal since random noise remains fairly constant and contributes $\approx 5 \%$, the effect of $\mathrm{HNO}_{3}$ correction is comparably negligible. The scatter found in experiments conducted under "identical" conditions was however considerably larger than $10 \%$, suggesting that experiment-to-experiment deviations in e.g. the morphology of the dust sample are responsible. We note that this analysis assumes that the projected geometric surface area is appropriate for extracting the uptake coefficient from the raw data. As described in detail before, this assumption can be tested by variation of the dust mass to estimate the role of diffusion of $\mathrm{N}_{2} \mathrm{O}_{5}$ into interstitial space within the bulk sample on the time scale of measurement of the initial signal drop (Keyser et al., 1991; Hanisch and Crowley, 2003b). Using previously reported bulk sample densities (Hanisch and Crowley, 2003b) and average particle diameters for identically prepared SDCV samples, we calculate that variation of the sample mass between 4 and $21 \mathrm{mg}$ is equivalent to variation of the number of layers between (very approximately) 40 and 200. This is similar to the range adopted in our experiments on $\mathrm{O}_{3}$ uptake to the same SDCV samples (Hanisch and Crowley, 2003b). Thinner samples could not be prepared using our procedure. The dependence of $\gamma_{\text {geom }}$ on the sample mass is illustrated in Fig. 11. In contrast to our experiments with $\mathrm{O}_{3}$, but similar to our experiments with $\mathrm{HNO}_{3}$ (Hanisch and Crowley, 2001a; Hanisch and Crowley, 2001b) no dependence on sample mass was found. The data listed in Table 2 also shows no dependence of $\gamma_{\text {geom }}$ on the initial concentration of $\mathrm{N}_{2} \mathrm{O}_{5}$ (varied over a factor of almost 4). The solid line though the SDCV dataset in Fig. 11 is a predicted dependence of $\gamma_{\text {geom }}$ on sample mass using the pore diffusion correction equations and physical parameters for SDCV from our previous publication (Hanisch and Crowley, 2003b) which are listed along with data for ATD and $\mathrm{CaCO}_{3}$ in Table 3. With the tortuosity factor kept at either 1 or 3 and the average particle diameter found from the AFT experiments $(\approx 0.9 \mu \mathrm{m})$, values of $\gamma_{\text {true }}$ of $\approx 1-2 \times 10^{-5}$ (i.e. a factor $\approx 3000$ lower than $\gamma_{\text {geom }}$ ) was found to reproduce the data adequately. We note however, that the dataset did not sample both the mass independent regime (large masses) and the strongly mass dependent regime at low dust masses, which precludes proper assessment of the applicability of the model and the usual

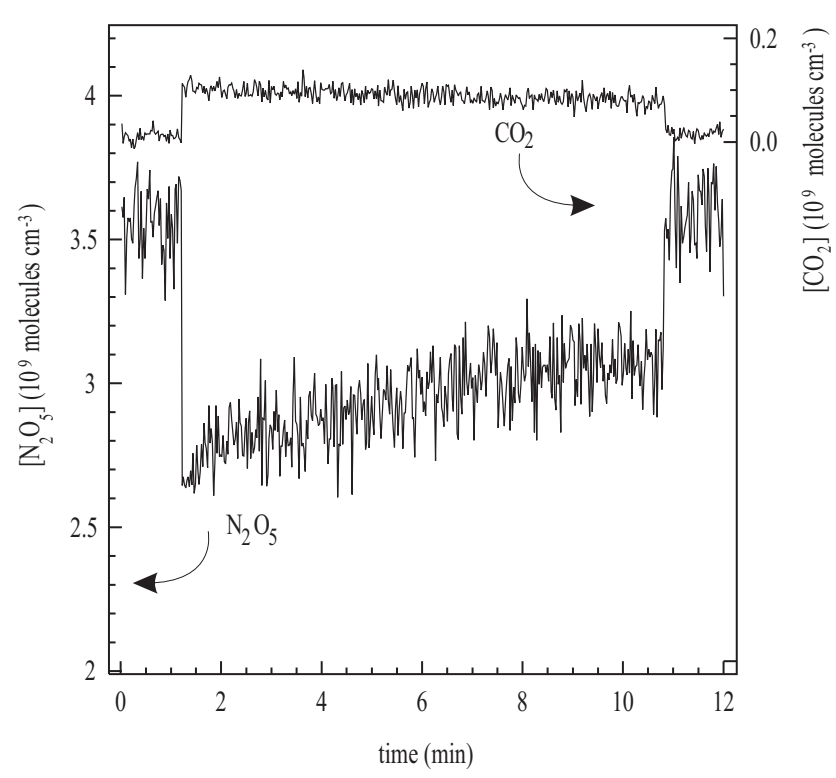

Fig. 12. Uptake of $\mathrm{N}_{2} \mathrm{O}_{5}$ to an unheated $\mathrm{CaCO}_{3}$ sample. $\mathrm{N}_{2} \mathrm{O}_{5}$ was measured at $m / z=46, \mathrm{CO}_{2}$ at $m / z=44$.

empirical derivation of the tortuosity factor. The choice of tortuosity factor of 1 or 3 was guided by the study of Boulter and Marschall (Boulter and Marschall, 2006), who suggest that values in excess of 3 are unlikely. Moreover, we note that the pore diffusion analysis requires knowledge of the average grain size, which ideally should be characterised by a narrow size distibution. Inspection of SEM pictures of our SDCV sample revealed a very wide range of sizes $(<0.3 \mu \mathrm{m}$ to $>10 \mu \mathrm{m}$ ) and it is unclear whether an average grain diameter based on the APS size is applicable. The application of the pore diffusion model to inhomogeneous, bulk samples is precarious and a more detailed analysis is, in this case, not warranted.

As shown in Fig. 10, during opening of the sample holder we also monitored $\mathrm{H}_{2} \mathrm{O}$ at $m / z=17\left(\mathrm{OH}^{+}\right)$and always observed some release of $\mathrm{H}_{2} \mathrm{O}$ from the sample (this effect was seen when no $\mathrm{N}_{2} \mathrm{O}_{5}$ was present) showing that some residual moisture resided in the bulk sample. No correlation was observed between the amount of water desorbing (a measure of the "dryness" of the sample) and the uptake coefficient. Products such as $\mathrm{CO}_{2}$ or $\mathrm{HNO}_{3}$ were not observed in these experiments.

\subsubsection{Arizona test dust}

Uptake coefficients for $\mathrm{N}_{2} \mathrm{O}_{5}$ on ATD were measured at five different sample masses and concentrations between 3.3 and $11 \times 10^{9}$ molecule $\mathrm{cm}^{-3}$. The data was qualitatively similar to that observed for SDCV, i.e. time independence of the signal during exposure and the treatment was identical.

The uptake coefficients are listed in Table 2 and plotted versus sample mass in Fig. 11. As for SDCV there is no significant dependence of the uptake coefficient on 
Table 2. Uptake coefficients and conditions for Knudsen reactor experiments.

\begin{tabular}{|c|c|c|c|c|c|c|c|c|}
\hline \multicolumn{3}{|c|}{ SDCV } & \multicolumn{3}{|c|}{ ATD } & \multicolumn{3}{|c|}{$\mathrm{CaCO}_{3}$} \\
\hline$\left[\mathrm{N}_{2} \mathrm{O}_{5}\right]^{\mathrm{a}}$ & $\operatorname{mass}^{b}$ & $\gamma^{\mathrm{c}}$ & {$\left[\mathrm{N}_{2} \mathrm{O}_{5}\right]^{\mathrm{a}}$} & $\operatorname{mass}^{b}$ & $\gamma^{\mathrm{c}}$ & {$\left[\mathrm{N}_{2} \mathrm{O}_{5}\right]^{\mathrm{a}}$} & mass $^{b}$ & $\gamma^{\mathrm{e}}$ \\
\hline 11.0 & 9.4 & $3.7 \pm 0.7$ & 10.4 & 10.7 & $2.0 \pm 0.4$ & 4.1 & 13.1 & $3.1 \pm 0.5$ \\
\hline 6.6 & 12.6 & $2.9 \pm 0.6$ & 6.8 & 20.5 & $2.1 \pm 0.4$ & 4.5 & 7.5 & $2.9 \pm 0.5$ \\
\hline 5.2 & 19.8 & $3.2 \pm 0.6$ & 4.1 & 6.5 & $2.6 \pm 0.5$ & 3.4 & 32.0 & $2.0 \pm 0.4$ \\
\hline 4.7 & 8.9 & $4.0 \pm 0.8$ & 3.3 & 5.9 & $2.5 \pm 0.5$ & 2.7 & 15.8 & $1.8 \pm 0.4$ \\
\hline 4.9 & 5.8 & $3.5 \pm 0.7$ & 3.5 & 7.7 & $2.0 \pm 0.4$ & 2.9 & 11.0 & $3.2 \pm 0.4$ \\
\hline 3.0 & 6.1 & $3.6 \pm 0.7$ & & & & 3.4 & 20.2 & $2.4 \pm 0.5$ \\
\hline 3.6 & 6.5 & $3.4 \pm 0.7$ & & & & 3.3 & 12.2 & $7.4 \pm 1.5 *$ \\
\hline 3.6 & 9.5 & $3.3 \pm 0.7$ & & & & 3.6 & 23.1 & $7.5 \pm 1.4^{*}$ \\
\hline 6.0 & 5.1 & $3.7 \pm 0.7$ & & & & 3.1 & 10.3 & $4.7 \pm 1.0 *$ \\
\hline 6.3 & 21.6 & $3.8 \pm 0.8$ & & & & 2.2 & 16.3 & $4.2 \pm 1.0 *$ \\
\hline 5.1 & 14.0 & $3.3 \pm 0.7$ & & & & 1.7 & 9.0 & $3.0 \pm 0.7 *$ \\
\hline 5.1 & 10.3 & $2.8 \pm 0.6$ & & & & & & \\
\hline 3.6 & 7.3 & $3.3 \pm 0.7$ & & & & & & \\
\hline 4.1 & 5.2 & $4.9 \pm 1.0$ & & & & & & \\
\hline 3.9 & 8.1 & $4.3 \pm 0.9$ & & & & & & \\
\hline 5.8 & 4.0 & $2.9 \pm 1.0^{\mathrm{d}}$ & & & & & & \\
\hline
\end{tabular}

All experiments were conducted at $296 \pm 2 \mathrm{~K}$.

a Concentrations in $10^{9}$ molecule $\mathrm{cm}^{3}$.

$\mathrm{b}$ Mass of sample per $\mathrm{cm}^{2}$.

c $\gamma\left(\times 10^{-2}\right)$ is reported for heated samples, unless denoted with a star (unheated).

$\mathrm{d}$ Obtained using the $2.25 \mathrm{~cm}^{2}$ sample holder.

e $\gamma\left(\times 10^{-2}\right)$ is the initial uptake coefficient.

Table 3. Physical charactierstics of the bulk dust samples used in pore diffusion calculations.

\begin{tabular}{lccc}
\hline & \multicolumn{3}{c}{ Dust Type } \\
\hline Parameter $\downarrow$ & SDCV & ATD & $\mathrm{CaCO}_{3}$ \\
\hline BET surface area $\left(\mathrm{m}^{2} / \mathrm{g}\right)$ & 39.6 & 5.7 & 5.1 \\
particle density $\left(\mathrm{g} / \mathrm{cm}^{3}\right)$ & 2.7 & 2.65 & 2.93 \\
sample density $\left(\mathrm{g} / \mathrm{cm}^{3}\right)$ & 1.2 & 1 & 1 \\
diameter $(\mu \mathrm{m})$ & 1 & $5^{\mathrm{a}}$ & $5^{\mathrm{a}}$ \\
\hline
\end{tabular}

${ }^{\text {a }}$ Estimated from SEM pictures of the sample.

sample mass or $\mathrm{N}_{2} \mathrm{O}_{5}$ concentration, with an average value of $\gamma_{\text {geom }}=(2.2 \pm 0.8) \times 10^{-2}$. The larger average particle diameter means that at $5 \mathrm{mg}$ sample mass, only about 10 formal layers of height $5 \mu \mathrm{m}$ are present. Under such conditions, the calculations for the pore diffusion analysis suggest that, due to the larger particles and lower BET surface areas, the linear mass dependent regime should extend beyond $15 \mathrm{mg} \mathrm{cm}^{-2}$. The pore diffusion calculations were initiated with tortuosity factors of 1 or 3 as for SDCV. Clearly, the predicted dependence of $\gamma_{\text {geom }}$ on sample mass is not observed in the dataset, suggesting that the $\mathrm{N}_{2} \mathrm{O}_{5}$ is not interacting significantly with internal surface area of the bulk sample. In order to align the model prediction with the dataset, an unrealistically large value for the tortuosity factors $(\approx 50)$ is required, implying that application of the pore diffusion model is inappropriate, and that (on the time scale of our experiments) reaction takes place mainly at the surface layer. We note that the use of the projected geometric surface area must however result in a value of the uptake coefficient that is an upper limit as, even in the absence of diffusion into the bulk sample, surface roughness is neglected. This may result in surface area enhancements of a factor of two or more, depending on the sample morphology and the grain size. As for SDCV, no significant release of $\mathrm{CO}_{2}$ could be observed.

\subsubsection{Calcite $\left(\mathrm{CaCO}_{3}\right)$}

A total of 11 experiments were conducted with both heated $(\approx 400 \mathrm{~K}$ for $>5 \mathrm{~h})$ and unheated $\mathrm{CaCO}_{3}$ samples. For the 6 heated samples (Fig. 11) the uptake coefficients were found to be similar to those found for ATD, with an average, mass independent value of the uptake coefficient of $(2.6 \pm 0.8) \times 10^{-2}$. A number of differences between the unheated and heated samples were observed, including a time dependent $\mathrm{N}_{2} \mathrm{O}_{5}$ signal during exposure to the unheated samples, with initially large uptake coefficients decreasing over a period of $10 \mathrm{~min}$. An example of a raw data set showing uptake to unheated $\mathrm{CaCO}_{3}$ is given in Fig. 12. For 
Table 4. Summary of laboratory studies of $\mathrm{N}_{2} \mathrm{O}_{5}$ uptake to mineral dust samples at room temperature.

\begin{tabular}{|c|c|c|c|c|}
\hline Dust & uptake coefficient $\left(10^{-2}\right)$ & method/RH & notes & Reference \\
\hline \multirow[t]{9}{*}{ SDCV } & $\gamma_{0}=8.0 \pm 0.3$ & Knudsen/0 \% & $\mathrm{a}$ & (Seisel et al., 2005) \\
\hline & $\gamma_{s s}=1.3 \pm 0.3$ & Knudsen/0\% & $\mathrm{a}$ & (Seisel et al., 2005) \\
\hline & $\gamma=0.91 \pm 0.07$ & DRIFTS/0\% & & (Seisel et al., 2005) \\
\hline & $\gamma_{0}=30 \pm 8$ & Knudsen/0\% & $\mathrm{b}$ & (Karagulian et al., 2006) \\
\hline & $\gamma_{s s}=20 \pm 5$ & Knudsen/0\% & $\mathrm{b}$ & (Karagulian et al., 2006) \\
\hline & $\gamma_{0}=\gamma_{s s}=3.7 \pm 1.2$ & Knudsen/0\% & $\mathrm{c}$ & This work \\
\hline & $\gamma=1.3 \pm 0.2$ & $\mathrm{AFT} / 0 \%$ & & This work \\
\hline & $\gamma=0.8 \pm 0.2$ & $\mathrm{AFT} / 29 \%$ & & This work \\
\hline & $\gamma=0.5 \pm 0.2$ & AFT/58\% & & This work \\
\hline \multirow[t]{3}{*}{ ATD } & $\gamma_{0}=20 \pm 6$ & Knudsen/0\% & $\mathrm{b}$ & (Karagulian et al., 2006) \\
\hline & $\gamma_{s s}=11 \pm 3$ & Knudsen/0\% & $\mathrm{b}$ & (Karagulian et al., 2006) \\
\hline & $\gamma_{0}=\gamma_{s s}=2.2 \pm 0.8$ & Knudsen/0\% & c & This work \\
\hline \multirow[t]{4}{*}{$\mathrm{CaCO}_{3}$} & $\gamma_{0}=12 \pm 4$ & Knudsen/0\% & $\mathrm{b}$ & (Karagulian et al., 2006) \\
\hline & $\gamma_{s s}=2.1 \pm 0.6$ & Knudsen/0\% & $\mathrm{b}$ & (Karagulian et al., 2006) \\
\hline & $\gamma_{0}=2.6 \pm 0.8$ & Knudsen, heated/0\% & $\mathrm{c}$ & This work \\
\hline & $\gamma_{0}=5 \pm 2$ & Knudsen, unheated $/ 0 \%$ & $\mathrm{~d}$ & This work \\
\hline
\end{tabular}

\footnotetext{
a Sample generated from aqueous slurry and dried under vacuum without heating.

b Sample dried at $294 \mathrm{~K}$ under vacuum until water desorption ceased.

${ }^{\mathrm{c}}$ Sample generated from slurry in methanol and dried under vacuum whilst heating to $450^{\circ} \mathrm{C}$.

d Sample generated from slurry in methanol and dried under vacuum without heating. For all Knudsen reactor experiments the uptake coefficient was derived from the projected, geometric surface area of the bulk sample and are thus upper limits.
}

this dataset, $\gamma$ decreased from a value of $7.5 \times 10^{-2}$ immediately after exposure started to a value of $3.6 \times 10^{-2}$ after $11 \mathrm{~min}, \approx$ a factor of two smaller. Note that the uptake coefficients listed in Table 2 are the initial (maximum) uptake coefficients.

Concurrent with the loss of $\mathrm{N}_{2} \mathrm{O}_{5}$ to the surface, we observed formation of $\mathrm{CO}_{2}$ (measured at $m / z=44$ ) which is closely anti-correlated with the $\mathrm{N}_{2} \mathrm{O}_{5}$ signal. On the time scale of the experiments, the $\mathrm{CO}_{2}$ is formed promptly. By calibrating the mass spectrometer for both $\mathrm{N}_{2} \mathrm{O}_{5}$ and $\mathrm{CO}_{2}$ we were able to calculate that the yield of $\mathrm{CO}_{2}$ per $\mathrm{N}_{2} \mathrm{O}_{5}$ lost to the surface was $0.09( \pm 0.02)$ for both the heated and unheated samples. This observation is qualitatively similar to previous results from this laboratory describing the interaction of $\mathrm{HNO}_{3}$ with $\mathrm{CaCO}_{3}$, which also produces $\mathrm{CO}_{2}$ though at a much higher $(\approx 30 \%)$ yield (Hanisch and Crowley, 2001a).

The results of the pore diffusion correction for $\mathrm{N}_{2} \mathrm{O}_{5}$ uptake to the bulk $\mathrm{CaCO}_{3}$ substrate is ambiguous. Considering only the data obtained with heated samples, we see that, when constrained by reasonable values of the tortuosity, the pore diffusion model cannot reproduce the independence of the uptake coefficient on sample mass. The data obtained using non heated samples displays higher values of the initial uptake coefficient with some apparent dependence on the sample mass, but also significantly more scatter which, in combination with a limited set of data, precludes an accurate pore diffusion analysis.

\section{Summary - comparison with literature and atmo- spheric implications}

The complete dataset from this study is compiled with previous literature determinations (Seisel et al., 2005; Karagulian et al., 2006) of uptake coefficients in Table 4. Values of the initial uptake coefficient (i.e. to a fresh surface) and a steady state uptake coefficient are noted, the Knudsen reactor experiments, both in the present study and in the literature used the geometric surface area to derive the uptake coefficient so that direct comparison should, in principle, be possible.

The most comprehensive dataset is for SDCV, for which Knudsen reactor derived initial uptake coefficients vary between $\approx 4 \times 10^{-2}$ and $30 \times 10^{-2}$ with some of this variability likely to be due to different methods of sample preparation as indicated in Table 4. Our Knudsen reactor result appears to be more consistent with the values reported by Seisel et al. (2005) rather than with Karagulian et al. (2006) who report significantly larger values for both initial and steady state uptake coefficients. This is surprising as Karagulian used the very same dust sample as we have. If the gas phase conditions were similar, the discrepancy can only be resolved by assuming significant changes in reactivity induced during sample preparation and sample presentation, or the presence of reactive species in the $\mathrm{N}_{2} \mathrm{O}_{5}$ flow. Though not mentioned in their manuscript, the samples of Karagulian et al. (2006) were "de-humidified" by evacuation at $294 \mathrm{~K}$ for $\approx 30 \mathrm{~min}$, or until $\mathrm{H}_{2} \mathrm{O}$ desorption stopped (F. Karagulian and M. J. Rossi, 


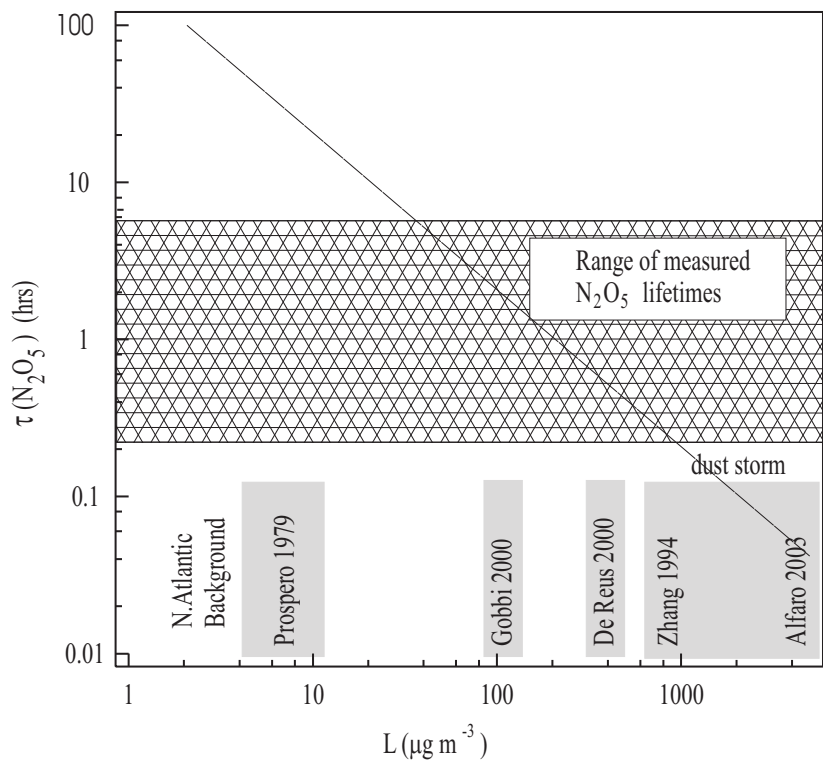

Fig. 13. $\mathrm{N}_{2} \mathrm{O}_{5}$ lifetime versus dust loading. The smooth line is the lifetime with respect to uptake to mineral aerosol based on the uptake coefficient measured in this work. Illustrative measurements of dust loadings (refs) and $\mathrm{N}_{2} \mathrm{O}_{5}$ lifetimes are also given. References are: Prospero $1979=($ Prospero, 1979) Gobbi $2000=($ Gobbi et al., 2000) De Reus $2000=$ (Reus et al., 2000) Zhang $1994=($ Zhang et al., 1994) Alfaro 2003 = (Alfaro et al., 2003). The literature source of the $\mathrm{N}_{2} \mathrm{O}_{5}$ lifetimes is given in the text.

personal communication, 2007). This procedure will leave more moisture associated with the bulk substrate than the heating/evacuating procedure adopted in the present study, and may contribute to the discrepancy in the values of $\gamma \mathrm{ob}$ served.

A similar picture emerges when the $\mathrm{CaCO}_{3}$ and ATD data of the same two groups are compared, with the uptake coefficients of Karagulian et al. (2006) significantly larger in all cases. Karagulian et al. (2006) observed a dependence of the uptake coefficient on $\mathrm{N}_{2} \mathrm{O}_{5}$ concentration, with larger values of $\gamma$ associated with lower concentrations. As our concentrations were significantly lower $(\approx$ factor 100$)$ than those used by Karagulian et al. (2006) this clearly cannot explain the discrepancy observed. A further difference in the two studies is the use of much larger sample masses by Karagulian et al. (2006) (100 and $1800 \mathrm{mg}$ ) and the observation of a dependence of $\gamma$ on sample mass between 0 and $300 \mathrm{mg}$, which was attributed to incomplete coverage of the sample support. Some of the differences noted above may be attributed to different modes of sample preparation (heating or not-heating during drying), as the non-heated samples from the present study yielded larger values of $\gamma$, than the heated samples. Indeed, a factor $\approx 2$ difference in $\gamma_{0}$ of Karagulian et al. (2006) and the present study for non-heated samples may be considered to be in reasonable agreement. Qualitative similarities between our Knudsen reactor work and that of Karagulian include the observation of $\mathrm{CO}_{2}$ release upon exposure of $\mathrm{CaCO}_{3}$ to $\mathrm{N}_{2} \mathrm{O}_{5}$. The yield of $\mathrm{CO}_{2}$ reported by Karagulian of $42-50 \%$ is however much larger than values of $9 \%$ in the present study. Once again the difference is most likely due to sample preparation and the amount of $\mathrm{H}_{2} \mathrm{O}$ available for reaction.

As already mentioned, issues related to porosity of the bulk samples can also influence the value of the uptake coefficient obtained from Knudsen reactor experiments. Although all of the studies using Knudsen reactors to investigate $\mathrm{N}_{2} \mathrm{O}_{5}$ uptake to mineral dust substrates have concluded that pore diffusion is not important, sample surface morphology (roughness) means that the projected geometric area is the minimum area with which collisions are taking place, and that the uptake coefficient so derived are upper limits. Indeed, sample roughness is not a parameter that is easily accessed by the Knudsen studies and will vary from study to study and contribute to scatter in reported values of $\gamma$ for seemingly identical processes.

Many of the uncertainties related to derivation of uptake coefficients when using porous or grainy bulk substrates in Knudsen reactors are eliminated in the AFT approach, and we consider the uptake coefficients presented for SDCV using the AFT to be more reliable. The agreement in the MPI data sets using both methods is quite satisfactory, yet, given the differences in literature values using Knudsen reactors to investigate this process, may to some extent be fortuitous. For the following discussion of the atmospheric implications of $\mathrm{N}_{2} \mathrm{O}_{5}$ uptake to mineral dust we consider only the AFT data on SDCV.

Table 1 reveals that, within experimental uncertainty, the measured uptake coefficient for Saharan dust from the AFT experiments is independent of most experimental variables including $\mathrm{N}_{2} \mathrm{O}_{5}$ concentration. This confirms that the experiments were carried out under conditions in which the number of reactive sites on the dust surface were not significantly depleted during the maximum $30 \mathrm{~s}$ exposure to $\mathrm{N}_{2} \mathrm{O}_{5}$. What is very surprising, however is that the uptake coefficient decreases with increasing relative humidity. As $\mathrm{N}_{2} \mathrm{O}_{5}$ uptake to surfaces is normally considered to be driven by hydrolysis and the availability of $\mathrm{H}_{2} \mathrm{O}$ at the surface, this is counterintuitive. We note that the uptake coefficient for $\mathrm{N}_{2} \mathrm{O}_{5}$ to aqueous surfaces has been determined to be close to 0.02 (see references cited by Evans and Jacob, 2005) which is larger by only a factor of $\approx$ two greater than our value obtained at zero humidity, making the existence of a strong $\mathrm{RH}$ dependence unlikely. Only for non-reactive uptake do we expect that competitive adsorption with $\mathrm{H}_{2} \mathrm{O}$ may reduce the apparent experimental uptake coefficient. As we have no evidence for a reversible component of the $\mathrm{N}_{2} \mathrm{O}_{5}$ uptake to mineral dust in the presence (or absence) of water this hypothesis remains unsubstantiated. We cannot rule out that the weak negative correlation between the uptake coefficient and RH may arise from an unidentified experimental systematic error, though further (more precise) investigations would to useful to resolve this issue. 
The AFT result of a large uptake coefficient at low RH is supported by the Knudsen reactor experiments on SDCV which yield slightly higher uptake coefficients (actually upper limits, see above) at a relative humidity of essentially zero.

The Knudsen reactor results for dry, bulk $\mathrm{CaCO}_{3}$ samples, which showed different reactivity if heated or not during drying under vacuum is also revealing in this respect. Water uptake isotherms for $\mathrm{CaCO}_{3}$ show that, at low RH, very little surface adsorbed $\mathrm{H}_{2} \mathrm{O}$ can be detected (Gustafsson et al., 2005 ) and suggest that the enhanced reactivity when comparing non-heated to heated samples is not due only to surface bound water. Compared to commercial $\mathrm{CaCO}_{3}$, Saharan dust contains a significantly larger amount of strongly bound water which is not removed under vacuum at ambient temperatures. Indeed, for some clay minerals water can contribute more than 10 percent to the overall mass, and this water can only be removed by heating to $\approx 800 \mathrm{~K}$ (Grim, 1953). The independence of $\gamma$ on the availability of $\mathrm{H}_{2} \mathrm{O}$ may thus simply reflect that Saharan dust (and clay minerals in general) is always associated with a large "internal" water content and that the reaction with $\mathrm{N}_{2} \mathrm{O}_{5}$ is not purely a surface phenomenon. In this vein, and as mentioned above, we note that the uptake coefficient for $\mathrm{N}_{2} \mathrm{O}_{5}$ to an aqueous surface at temperatures close to $300 \mathrm{~K}$ is characterised by an uptake coefficient of close to $2 \times 10^{-2}$, not much larger than that observed for "dry" or "humid" SDCV. In the following calculations, we thus assume that the uptake of $\mathrm{N}_{2} \mathrm{O}_{5}$ to mineral dust in the atmosphere is characterised by a single uptake coefficient, independent of e.g. T or RH.

Neglecting limitations due to diffusive transport, the lifetime of a trace gas ( $\tau$, in s) with respect to uptake to an aerosol surface may be calculated using the following expression:

$$
\tau=\frac{4}{\gamma \cdot \bar{c} \cdot A}
$$

where $A$ is the surface area of aerosol per volume of gas $\left(\mathrm{cm}^{2} \mathrm{~cm}^{-3}\right)$. As dust aerosol loading $(L)$ is usually presented in $\mu \mathrm{g} \mathrm{m}^{-3}$, we note that, by assuming an average particle diameter of $1 \mu \mathrm{m}$ and density of $2.7 \mathrm{~g} \mathrm{~cm}^{-3}, 1 \mu \mathrm{g} \mathrm{m}^{-3}$ results in a surface area density of $2.2 \times 10^{-8} \mathrm{~cm}^{2} \mathrm{~cm}^{-3}$. Expression (13) then becomes:

$\tau=\frac{4}{\gamma \cdot \bar{c} \cdot L} \cdot 4.5 \times 10^{7}$

The dependence of the $\mathrm{N}_{2} \mathrm{O}_{5}$ lifetime $\left(\tau_{\mathrm{N}_{2} \mathrm{O}_{5}}\right)$ on mineral dust loading is presented in Fig. 13, whereby an uptake coefficient of $1 \times 10^{-2}$ is used in the calculation. Field measurements of $\mathrm{N}_{2} \mathrm{O}_{5}$ have revealed a pseudo steady state lifetime (shaded area in Fig. 13) which can vary typically between $\approx 5 \mathrm{~min}$ and $2 \mathrm{~h}$ (but sometimes as large as $5 \mathrm{~h}$ ) and which depends heavily on e.g. available aerosol (Heintz et al., 1996; Martinez et al., 2000; Wood et al., 2005; Aldener et al., 2006). Clearly, background dust loading of e.g. $\approx 14 \mu \mathrm{g} \mathrm{m}^{-3}$ in the tropical North Atlantic and $\approx 4$ $5 \mu \mathrm{g} \mathrm{m}^{-3}$ in the Mediterranean and Indian Ocean (Prospero, 1979; Prospero and Nees, 1986) will contribute only insignificantly to $\mathrm{N}_{2} \mathrm{O}_{5}$ loss rates. At intermediate loadings (50 to $100 \mu \mathrm{g} \mathrm{m}^{-3}$ ) mineral dust can represent an important sink for $\mathrm{N}_{2} \mathrm{O}_{5}$ if e.g. the sulphate loading is low, whereas at loadings above $200 \mu \mathrm{g} \mathrm{m}^{-3}$, mineral dust can provide sufficient reactive surface to become the dominant sink.

Acknowledgements. We thank L. Gomes for his kind provision of the Saharan dust sample used in this study, and J. Schneider (MPI) for the loan of and assistance with the ELPI. Sections of this study were carried out in part fulfilment of the $\mathrm{PhD}$ of $\mathrm{CW}$ at the Johannes-Gutenberg University in Mainz. We are grateful for partial funding of this work (Knudsen reactor studies) within the EU project MINATROC (EVK2-1999-00003).

Edited by: J. Thornton

\section{References}

Aldener, M., Brown, S. S., Stark, H., Williams, E. J., Lerner, B. M., Kuster, W. C., Goldan, P. D., Quinn, P. K., Bates, T. S., Fehsenfeld, F. C., and Ravishankara, A. R.: Reactivity and loss mechanisms of $\mathrm{NO}_{3}$ and $\mathrm{N}_{2} \mathrm{O}_{5}$ in a polluted marine environment: Results from in situ measurements during New England Air Quality Study 2002, J. Geophys. Res., 111, D23S73, doi:10.1029/2006JD007252, 2006.

Alfaro, S. C., Gomes, L., Rajot, J. L., Lafon, S., Gaudichet, A., Chatenet, B., Maille, M., Cautenet, G., Lasserre, F., Cachier, H., and Zhang, X. Y.: Chemical and optical characterization of aerosols measured in spring 2002 at the ACE-Asia supersite, Zhenbeitai, China, J. Geophys. Res., 108, 8461, doi:10.1029/2002JD003214, 2003.

Ansmann, A., Mattis, I., Muller, D., Wandinger, U., Radlach, M., Althausen, D., and Damoah, R.: Ice formation in Saharan dust over central Europe observed with temperature/humidity//aerosol Raman lidar, J. Geophys. Res., 110, D18S12, doi:10.1029/2004JD005000, 2005.

Bauer, S. E., Balkanski, Y., Schulz, M., Hauglustaine, D. A., and Dentener, F.: Global modeling of heterogeneous chemistry on mineral aerosol surfaces: Influence on tropospheric ozone chemistry and comparison to observations, J. Geophys. Res., 109, D02304, doi:10.1029/2003JD003868, 2004.

Bian, H. S. and Zender, C. S.: Mineral dust and global tropospheric chemistry: Relative roles of photolysis and heterogeneous uptake, J. Geophys. Res., 108, 4672, doi:10.1029/2002JD003143, 2003.

Boulter, J. E. and Marschall, J.: Measurement of effective Knudsen diffusion coefficients for powder beds used in heterogeneous uptake experiments, J. Phys. Chem. A, 110, 10 444-10 455, 2006.

Brown, R. L.: Tubular flow reactors with first-order kinetics, J. Res. Nat. Bur. Standards, 83, 1-8, 1978.

Carmichael, G. R., Zhang, Y., Chen, L.-L., Hong, M.-S., and Ueda, H.: Seasonal variation of aerosol composition at Cheju island, Korea, Atmos. Environ., 30, 2407-2416, 1996.

Carstens, T.: Labormessungen kinetischer Parameter zur Beschreibung der Spurengasaufnahme in atmosphphärische Wassertröpfchen, University of Bonn, 1998. 
Chartrand, D. J. and McConnell, J. C.: Heterogeneous chemistry and the $\mathrm{O}_{3}$ budget in the lower mid- latitude stratosphere, J. Atmos. Chem., 35, 109-149, 1999.

Chester, R. and Johnson, L. R.: Atmospheric dusts collected off West African coast, Nature, 229, 105-107, 1971.

Curtis, A. R. and Sweetenham, W. P.: Facsimile, AERE, Report R-12805, 1987.

Dentener, F. J., Carmichael, G. R., Zhang, Y., Lelieveld, J., and Crutzen, P. J.: Role of mineral aerosol as a reactive surface in the global troposphere, J. Geophys. Res., 101, 22 869-22 889, 1996.

Dentener, F. J. and Crutzen, P. J.: Reaction of $\mathrm{N}_{2} \mathrm{O}_{5}$ on tropospheric aerosols - Impact on the global distributions of $\mathrm{NOx}, \mathrm{O}_{3}$, and OH, J. Geophys. Res., 98, 7149-7163, 1993.

Evans, M. J. and Jacob, D. J.: Impact of new laboratory studies of $\mathrm{N}_{2} \mathrm{O}_{5}$ hydrolysis on global model budgets of tropospheric nitrogen oxides, ozone, and OH, Geophys. Res. Lett., 32, L09813, doi:10.1029/2005GL022469, 2005.

Fahey, D. W., Eubank, C. S., Hübler, G., and Fehsenfeld, F. C.: A calibrated source of $\mathrm{N}_{2} \mathrm{O}_{5}$, Atmos. Environ., 19, 1883-1890, 1985.

Fried, A., Henry, B. E., Calvert, J. G., and Mozurkewich, M.: The Reaction Probability of N2O5 With Sulfuric-Acid Aerosols At Stratospheric Temperatures and Compositions, J. Geophys. Res., 99, 3517-3532, 1994.

Fuchs, N. A. and Sutugin, A. G.: Higly dispersed aerosols, Ann Arbor Sci., Ann Arbor, 1970.

Gobbi, G. P., Barnaba, F., Giorgi, R., and Santacasa, A.: Altituderesolved properties of Saharan dust event over the mediterranean, Atmos. Environ., 34, 5119-5127, 2000.

Gomes, L. and Gillette, D. A.: A comparison of characteristics of aerosol from dust storms in central Asia with soil-derived dust from other regions, Atmos. Environ., 27A, 2539-2544, 1993.

Grim, R. E.: Clay Mineralogy, McGraw-Hill, New York, 1953.

Gustafsson, R. J., Orlov, A., Badger, C. L., Griffiths, P. T., Cox, R. A., and Lambert, R. M.: A comprehensive evaluation of water uptake on atmospherically relevant mineral surfaces: DRIFT spectroscopy, thermogravimetric analysis and aerosol growth measurements, Atmos. Chem. Phys., 5, 3415-3421, 2005, http://www.atmos-chem-phys.net/5/3415/2005/.

Hanisch, F. and Crowley, J. N.: Heterogeneous reactivity of gaseous nitric acid on $\mathrm{Al}_{2} \mathrm{O}_{3}, \mathrm{CaCO}_{3}$, and atmospheric dust samples: A Knudsen cell study, J. Phys. Chem., 105, 3096-3106, 2001a.

Hanisch, F. and Crowley, J. N.: The heterogeneous reactivity of gaseous nitric acid on authentic mineral dust samples, and on individual mineral and clay mineral components, Phys. Chem. Chem. Phys., 3, 2474-2482, 2001 b.

Hanisch, F. and Crowley, J. N.: heterogeneous reactivity of NO and $\mathrm{HNO}_{3}$ on mineral dust in the presence of ozone, Phys. Chem. Chem. Phys., 5, 883-887, 2003 a.

Hanisch, F. and Crowley, J. N.: Ozone destruction on Saharan dust: An experimental investigation, Atmos. Chem. Phys., 3, 119-130, 2003 b.

Heintz, F., Platt, U., Flentje, H., and Dubois, R.: Long-term observation of nitrate radicals at the Tor station, Kap Arkona (Ruegen), J. Geophys. Res., 101, 22 891-22 910, 1996.

Hendricks, J., Lippert, E., Petry, H., and Ebel, A.: Heterogeneous reactions on and in sulfate aerosols: Implications for the chemistry of the midlatitude tropopause region, J. Geophys. Res., 104, 5531-5550, 1999.
Hinds, W. C.: Aerosol Technology, John Wiley \& Sons, New York, 1999.

$\mathrm{Hu}$, J. H. and Abbatt, J. P. D.: Reaction probabilities for $\mathrm{N}_{2} \mathrm{O}_{5}$ hydrolysis on sulfuric acid and ammonium sulfate aerosols at room temperature, J. Phys. Chem. A, 101, 871-878, 1997.

Hwang, H. J. and Ro, C. U.: Single-particle characterization of four aerosol samples collected in ChunCheon, Korea, during Asian dust storm events in 2002, J. Geophys. Res., 110, D23201, doi:10.1029/2005JD006050, 2005.

Immler, F. and Schrems, O.: Vertical profiles, optical and microphysical properties of Saharan dust layers determined by a shipborne lidar, Atmos. Chem. Phys., 3, 1353-1364, 2003, http://www.atmos-chem-phys.net/3/1353/2003/.

Karagulian, F. and Rossi, M.J.: The heterogeneous chemical kinetics of $\mathrm{NO}_{3}$ on atmospheric mineral dust surrogates, Phys. Chem. Chem. Phys., 7, 3150-3162, 2005.

Karagulian, F., Santschi, C., and Rossi, M. J.: The heterogeneous chemical kinetics of $\mathrm{N}_{2} \mathrm{O}_{5}$ on $\mathrm{CaCO}_{3}$ and other atmospheric mineral dust surrogates, Atmos. Chem. Phys., 6, 1373-1388, 2006, http://www.atmos-chem-phys.net/6/1373/2006/.

Keyser, L. F., Moore, S. B., and Leu, M.-T.: Surface-Reaction and Pore Diffusion in Flow-Tube Reactors, J. Phys. Chem., 95, 54965502, 1991.

Levin, Z., Price, C., and Ganor, E.: The contribution of sulfate and desert aerosols to the acidification of clouds and rain in Israel, Atmos. Environ., 24A, 1143-1151, 1990.

Lovejoy, E. R. and Hanson, D. R.: Measurement of the kinetics of reactive uptake by submicron sulfuric-acid particles, J. Phys. Chem., 99, 2080-2087, 1995.

Loyë-Pilot, M. D., Martin, J. M., and Morelli, J.: Influence of Saharan dust on the rain acidity and atmospheric input to the Mediterranean, Nature, 321, 427-428, 1986.

Lunt, D. J. and Valdes, P. J.: The modern dust cycle: Comparison of model results with observations and study of sensitivities, J. Geophys. Res., 107, 4669, doi:10.1029/2002JD002316, 2002.

Luo, C., Mahowald, N. M., and del Corral, J.: Sensitivity study of meteorological parameters on mineral aerosol mobilization, transport, and distribution, J. Geophys. Res., 108, 4447, doi:10.1029/2003JD003483, 2003.

Martinez, M., Perner, D., Hackenthal, E. M., Kulzer, S., and Schutz, L.: $\mathrm{NO}_{3}$ at Helgoland during the NORDEX campaign in October 1996, J. Geophys. Res., 105, 22 685-22 695, 2000.

Matsuki, A., Iwasaka, Y., Shi, G. Y., Zhang, D.Z., Trochkine, D., Yamada, M., Kim, Y.S., Chen, B., Nagatani, T., Miyazawa, T., Nagatani, M., and Nakata, H.: Morphological and chemical modification of mineral dust: Observational insight into the heterogeneous uptake of acidic gases, Geophys. Res. Lett., 32, L22806, doi:10.1029/2005GL0244176, 2005.

Meskhidze, N., Chameides, W. L., and Nenes, A.: Dust and pollution: A recipe for enhanced ocean fertilization?, J. Geophys Res., 110, D03301, doi:10.1029/JD005082, 2005.

Monchick, L. and Mason, E. A.: Transport properties of polar gases, J. Chem. Phys., 35, 1676-1697, 1961.

Mori, I., Nishikawa, M., Tanimura, T., and Quan, H.: Change in size distribution and chemical composition of kosa (Asian dust) aerosol during long-range transport, Atmos. Environ., 37, 42534263, 2003.

Nishikawa, M. and Kanamori, S.: Chemical composition of kosa 
aerosol (yellow sand dust) collected in Japan, Anal. Sci., 7, 1127-1130, 1991.

Okada, K., Kobayashi, A., Iwasaka, Y., Naruse, H., Tanaka, T., and Nemoto, O.: Features of individual Asian dust storm particles collected at Nagoya, Japan, J. Met. Soc. Japan, 65, 515-521, 1987.

Phadnis, M. J. and Carmichael, G. R.: Numerical investigation of the influence of mineral dust on the tropospheric chemistry of East Asia, J. Atmos. Chem., 36, 285-323, 2000.

Prospero, J. M.: Mineral and sea-salt concentrations in various ocean regions, J. Geophys. Res., 84, 725-731, 1979.

Prospero, J. M. and Nees, R. T.: Impact of the North African drought and El Niño on mineral dust in the Barbados trade winds, Nature, 320, 735-738, 1986.

Reus, D. M., Dentener, F., Thomas, A., Borrmann, S., Strom, J., and Lelieveld, J.: Airborne observations of dust aerosol over the North Atlantic Ocean during ACE 2: Indications for heterogeneous ozone destruction, J. Geophys. Res., 105, 15 263-15 275, 2000.

Sander, S. P., Friedl, R. R., Golden, D. M., Kurylo, M. J., Huie, R. E., Orkin, V. L., Moortgat, G. K., Ravishankara, A. R., Kolb, C. E., Molina, M. J., and Finlayson-Pitts, B. J., Chemical kinetics and photochemical data for use in atmospheric studies: Evaluation Number 15, Jet Propulsion Laboratory, National Aeronautics and Space Administration/Jet Propulsion Laboratory/California Institute of Technology, Pasadena, CA, 2006.

Sassen, K., DeMott, P. J., Prospero, J. M., and Poellot, M. R.: Saharan dust storms and indirect aerosol effects on clouds: CRYSTAL-FACE results, Geophys. Res. Lett., 30, 1633, doi:10.1029/2003GL017371, 2003.

Seisel, S., Borensen, C., Vogt, R., and Zellner, R.: Kinetics and mechanism of the uptake of $\mathrm{N}_{2} \mathrm{O}_{5}$ on mineral dust at $298 \mathrm{~K}$, Atmos. Chem. Phys., 5, 3423-3432, 2005, http://www.atmos-chem-phys.net/5/3423/2005/.

Shon, Z. H., Kim, K. H., Bower, K. N., Lee, G., and Kim, J.: Assessment of the photochemistry of $\mathrm{OH}$ and $\mathrm{NO}_{3}$ on Jeju Island during the Asian-dust-storm period in the spring of 2001, Chemosphere, 55, 1127-1142, 2004.
Silva, P. J., Carlin, R. A., and Prather, K. A.: Single particle analysis of suspended soil dust from Southern California, Atmos. Environ., 34, 1811-1820, 2000.

Song, C. H. and Carmichael, G. R.: Gas-particle partitioning of nitric acid modulated by alkaline aerosol, J. Atmos. Chem., 40, 1-22, 2001.

Tegen, I., Harrison, S. P., Kohfeld, K., Prentice, I. C., Coe, M., and Heimann, M.: Impact of vegetation and preferential source areas on global dust aerosol: Results from a model study, J. Geophys. Res., 107, 4567, doi:10.1026/2001JD000963, 2002.

Twomey, S. A., Piepgrass, M., and Wolfe, T.: An assessment of the impact of pollution on global cloud albedo, Tellus, 36B, 243249, 1984 .

Wayne, R. P., Barnes, I., Biggs, P., Burrows, J. P., Canosa-Mas, C. E., Hjorth, J., Le Bras, G., Moortgat, G. K., Perner, D., Poulet, G., Restelli, G., and Sidebottom, H.: The nitrate radical: Physics, chemistry, and the atmosphere, Atmos. Environ., 25A, 1-206, 1991.

Wood, E. C., Bertram, T. H., Wooldridge, P. J., and Cohen, R. C.: Measurements of $\mathrm{N}_{2} \mathrm{O}_{5}, \mathrm{NO}_{2}$ and $\mathrm{O}_{3}$ east of the San Francisco Bay, Atmos. Chem. Phys., 5, 483-491, 2005, http://www.atmos-chem-phys.net/5/483/2005/.

Zasypkin, A. Y., Grigoreva, V. M., Korchak, V. N., and Gershenson, Y. M.: A formula for summing of kinetic resistances for mobile and stationary media: 1. Cylindrical reactor, Kinet. Catal., 38, 772-781, 1997.

Zhang, Y., Sunwoo, Y., Kotamarthi, V., and Carmichael, G. R.: Photochemical oxidant processes in the presence of dust: An evaluation of the impact of dust on particulate nitrate and ozone formation, J. Appl. Met., 33, 813-824, 1994. 